BNL-114156-2017-JA

\title{
The Phenology of Leaf Quality and its Within-Canopy Variation are Essential for Accurate Modeling of Photosynthesis in Tropical Evergreen Forests
}

\author{
J. Wu \\ Accepted for publication in Global Change Biology
}

May 2017

Environmental \& Climate Science Dept.

Brookhaven National Laboratory

\author{
U.S. Department of Energy \\ USDOE Office of Science (SC), \\ Biological and Environmental Research (BER) (SC-23)
}




\section{DISCLAIMER}

This report was prepared as an account of work sponsored by an agency of the United States Government. Neither the United States Government nor any agency thereof, nor any of their employees, nor any of their contractors, subcontractors, or their employees, makes any warranty, express or implied, or assumes any legal liability or responsibility for the accuracy, completeness, or any third party's use or the results of such use of any information, apparatus, product, or process disclosed, or represents that its use would not infringe privately owned rights. Reference herein to any specific commercial product, process, or service by trade name, trademark, manufacturer, or otherwise, does not necessarily constitute or imply its endorsement, recommendation, or favoring by the United States Government or any agency thereof or its contractors or subcontractors. The views and opinions of authors expressed herein do not necessarily state or reflect those of the United States Government or any agency thereof. 
1 The phenology of leaf quality and its within-canopy variation are essential for accurate modeling

2 3

\section{of photosynthesis in tropical evergreen forests}

Running Head: Modeling tropical photosynthetic seasonality

\section{Authors}

Jin $\mathrm{Wu}^{1 *}$, Shawn P. Serbin ${ }^{1}$, Xiangtao $\mathrm{Xu}^{2}$, Loren P. Albert ${ }^{3}$, Min Chen ${ }^{4,5}$, Ran Meng ${ }^{1}$, Scott R. Saleska $^{3}$, Alistair Rogers ${ }^{1}$

\section{Institute or laboratory of origin}

[1] Environmental \& Climate Sciences Department, Brookhaven National Laboratory, Upton, New York, NY, 11973

[2] Department of Geosciences, Princeton University, Princeton, NJ, 08544

[3] Department of Ecology and Evolutionary Biology, University of Arizona, Tucson, AZ, 85721

[4] Department of Global Ecology, Carnegie Institution for Science, Stanford, CA, 94305

[5] Joint Global Change Research Institute, Pacific Northwest National Laboratory, College Park, MD, 20740

* Corresponding author: 631-344 3361; jinwu@bnl.gov

Key words: big leaf; sun/shade; multi-layer; light use efficiency; gross primary productivity; leaf age; leaf area index; photosynthetic capacity

Type of Paper: Original Research 


\section{Abstract:}

28 Leaf quantity (i.e. canopy leaf area index, LAI), quality (i.e. per-area photosynthetic capacity), 29 and longevity all influence the photosynthetic seasonality of tropical evergreen forests. However, 30 these components of tropical leaf phenology are poorly represented in most terrestrial biosphere models (TBMs). Here, we explored alternative options for the representation of leaf phenology

32 effects in TBMs that employ the Farquahar, von Caemmerer \& Berry (FvCB) representation of $33 \mathrm{CO}_{2}$ assimilation. We developed a two-fraction leaf (sun and shade), two-layer canopy (upper 34 and lower) photosynthesis model to evaluate different modeling approaches and assessed three 35 components of phenological variations (i.e. leaf quantity, quality, and within-canopy variation in 36 leaf longevity). Our model was driven by the prescribed seasonality of leaf quantity and quality 37 derived from ground based measurements within an Amazonian evergreen forest. Modeled photosynthetic seasonality was not sensitive to leaf quantity, but was highly sensitive to leaf 39 quality and its vertical distribution within the canopy, with markedly more sensitivity to upper canopy leaf quality. This is because light absorption in tropical canopies is near maximal for the

41 entire year, implying that seasonal changes in LAI have little impact on total canopy light 42 absorption; and because leaf quality has a greater effect on photosynthesis of sunlit leaves than 43 light limited, shade leaves and sunlit foliage are more abundant in the upper canopy. Our two44 fraction leaf, two-layer canopy model which accounted for all three phenological components 45 was able to simulate photosynthetic seasonality, explaining $\sim 90 \%$ of the average seasonal 46 variation in eddy covariance derived $\mathrm{CO}_{2}$ assimilation. This work identifies a parsimonious 47 approach for representing tropical evergreen forest photosynthetic seasonality in TBMs that utilize the $\mathrm{FvCB}$ model of $\mathrm{CO}_{2}$ assimilation, and highlights the importance of incorporating more 
49 realistic phenological mechanisms in models that seek to improve the projection of future carbon 50 dynamics in tropical evergreen forests. 


\section{Introduction}

52

53

54

Tropical evergreen forests play a dominant role in the global carbon, water, and energy cycles (Pan et al., 2011; Fu et al., 2013; Stark et al., 2016). They account for around one-third of annual terrestrial photosynthesis (Beer et al., 2010) and a quarter of the global aboveground carbon stock (Saatchi et al., 2011; Aragao et al., 2014). Therefore, even small errors in model representation of the carbon pools or fluxes in this biome will result in marked uncertainty in the projection of future climate (Friedlingstein et al., 2006, 2014; Cox et al., 2013; Huntingford et al., 2013). A key area of uncertainty is our understanding and model representation of tropical evergreen forest seasonality, including seasonal leaf display as well as physiological function (Saleska et al., 2003; Restrepo-Coupe et al., 2013; Guan et al., 2015). Most Terrestrial Biosphere Models (TBMs) have a mechanistic representation of $\mathrm{CO}_{2}$ assimilation that is capable of simulating the response of photosynthesis to global change (e.g. increasing atmospheric $\mathrm{CO}_{2}$ concentration). However, most of these models lack mechanistic representation of tropical forest photosynthetic seasonality (de Weirdt et al., 2012, Kim et al., 2012; Restrepo-Coupe et al., 2017). To improve our ability to project the impact of global change on the terrestrial carbon cycle, we need to integrate model representation of the mechanisms that regulate tropical forest photosynthetic seasonality with an approach that is capable of mechanistically representing the response of photosynthesis to global change.

Within tropical evergreen forests, leaf production from field based studies (e.g. Wright \& van Schaik, 1994; Girardin et al., 2016), and canopy photosynthesis (i.e. gross primary productivity, GPP) derived from eddy flux towers (Saleska et al., 2003; Hutyra et al., 2007; Restrepo-Coupe et al., 2013) and satellites (Lee et al., 2013; Guan et al., 2015) consistently show seasonal variability. Importantly, this seasonal variation is not directly related to extrinsic 
74 environmental variability (Bradley et al., 2011; Guan et al., 2015; Wu et al., 2016a, 2017).

75 Instead, increasing evidence has shown that tropical leaf phenology is a primary mechanism 76 regulating seasonal carbon assimilation (Doughty \& Goulden, 2008; Kim et al., 2012; Restrepo77 Coupe et al., 2013; Wu et al., 2016a, 2017). Here phenology refers to periodic cycles of leaf 78 production, development and abscission within a forest canopy, which produces seasonal 79 variability in leaf quantity (i.e. canopy leaf area index, LAI) and leaf quality (i.e. per-area leaf 80 photosynthetic capacity), and includes the differential leaf turnover associated with the changes

81 in leaf longevity within vertical canopy profiles. Despite a modest seasonality in leaf quantity 82 (e.g. Doughty \& Goulden, 2008; Brando et al., 2010; Lopes et al., 2016; Saleska et al., 2016), many tropical evergreen forests exhibit substantial leaf turnover during the dry season when 84 monthly precipitation is lower than the evaporative demand (Borchert, 1994; Wright \& van 85 Schaik, 1994; Wu et al., 2016a; Lopes et al., 2016). As a result, these forests have a strong 86 seasonality in leaf quality because recently mature leaves have a higher photosynthetic capacity 87 than the old leaves they replace (Kitajima et al., 1997a; Doughty \& Goulden, 2008; Wu et al., 2016a). Importantly, this seasonal variation in leaf quality was recently shown to be one of the 89 most important phenological mechanisms responsible for photosynthetic seasonality in tropical evergreen forests (Wu et al., 2016a, 2017). However, this advance (e.g. Wu et al., 2016a, 2017)

91 was based on a light use efficiency model that can capture tropical forest photosynthetic 92 seasonality but lacks the physiological and structural complexity that is necessary to project the 93 response to the changing climate, particularly rising $\mathrm{CO}_{2}$ concentration. In addition to leaf quality and quantity, the within canopy variation in leaf longevity has 95 been well documented in the tropics (e.g. Lowman, 1992; Miyaji et al., 1997; Reich et al., 2004). 96 This large within-canopy variation in leaf phenological characteristics, with understory leaves 
97 living two or more times longer than canopy leaves, may be attributed either to temporal niche

98 partitioning between canopy trees and the understory (Messier et al., 1998; Augspurger et al., 99 2005; Richardson \& O’Keefe, 2009), or to an adaptive response to large within-canopy variation 100 in environmental variables (Wright et al., 2006; Stark et al., 2012, 2015; Niinemets et al., 2015). 101 As such, within-canopy variation in light and associated biotic properties have also been 102 suggested as an important control on processes such as leaf development, energy balance, water 103 use, and photosynthesis (Ellsworth \& Reich, 1993; Baldocchi \& Amthor, 2001; Stark et al., 104 2012; Morton et al., 2016).

105 Despite the importance of leaf phenology in regulating photosynthetic seasonality in the 106 tropics, the combined effects of these three phenological components on tropical forest 107 photosynthetic seasonality are either absent or have not been adequately represented in current 108 TBMs (e.g. Restrepo-Coupe et al., 2017). The majority of TBMs (e.g. Fisher et al., 2015; Rogers 109 et al., 2017) utilize the Farquhar, von Caemmerer and Berry (1980) (FvCB) leaf scale 110 mechanistic model of $\mathrm{CO}_{2}$ assimilation to simulate carbon uptake together with a leaf to canopy 111 scaling relationship, which often represents the whole forest canopy as sunlit and shade leaf 112 fractions (e.g. dePury \& Farquhar, 1997; Drewry et al., 2010). Several modeling attempts have 113 been proposed to improve the representation of photosynthetic seasonality. For example, some 114 TBMs have included seasonal variation in LAI driven by water availability (Baker et al., 2008; 115 Powell et al., 2013; Sitch et al., 2015; Xu et al., 2016; Restrepo-Coupe et al., 2017); however, 116 the representation of seasonal change in leaf quality and their vertical distribution has rarely been 117 explored before. As a result, these models generally fail to adequately reproduce the 118 photosynthetic seasonality of tropical evergreen forests, simulating a dry-season photosynthetic 119 decrease as a consequence of increasing dry-season water stress, with eddy covariance derived 
120 GPP showing the opposite trend (Saleska et al., 2003; Baker et al., 2008; de Goncalves et al., 121 2013; Restrepo-Coupe et al., 2017). Several other attempts have shown some improvement in the 122 modeling performance of TBM-based photosynthetic seasonality by tuning model parameters to 123 allow for seasonal variation in leaf photosynthetic capacity (e.g. de Weirdt et al., 2012; Kim et 124 al., 2012). However, the assumptions made in these models, such as the application of the leaf 125 economic spectrum to within-canopy relationships, require systematic evaluation (Messier et al., 126 representation of leaf phenology effects on tropical evergreen forest photosynthesis that includes all three phenological components of leaf quantity, quality, and differential leaf turnover within a forest canopy. 2016) or compared to field based metrics of both leaf phenology (e.g. leaf production and senescence) and GPP. The model-observation mismatch and the incomplete mechanistic evaluation highlight need for improving current TBMs which should include a mechanistic

The goal of this study was to develop an approach that would provide the sufficient phenological representation of the three components to capture the photosynthetic seasonality of 134 a tropical evergreen forest in a mechanistic model framework that included the FvCB 135 representation of $\mathrm{CO}_{2}$ assimilation and a multilayer canopy. We accomplished this by evaluating 136 the performance of model structures that incorporated the three different phenological 137 mechanisms. We asked three questions: (1) Is seasonality of tropical forest photosynthesis 138 reproduced by a model including leaf phenology? (2) What is the relative contribution of these 139 three phenological components in controlling the seasonality of photosynthesis? (3) Finally, how 140 do these three components regulate tropical forest photosynthetic seasonality? 
143 canopy photosynthetic seasonality. In addition, we enabled representation of sun and shade leaf 144 fractions and a two-layer canopy (upper and lower) to allow us to explore within-canopy 145 phenological variation. As such, our model framework allowed us to assess how the three 146 components of leaf phenology independently and jointly regulated canopy-scale photosynthetic 147 seasonality. In order to evaluate the model performance and avoid other confounding factors in 148 our analysis, such as seasonal and inter-annual environmental variation (Baldocchi \& Amthor,

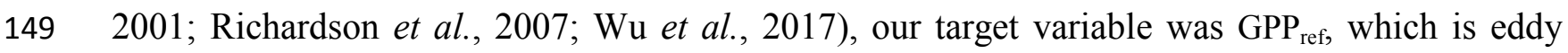
150 covariance derived or modeled GPP under a reference environment. This enabled us to focus on 151 the underlying physiological mechanisms and isolate the biological controls on GPP from 152 seasonality in environmental variables (Wu et al., 2017). The successful attribution of biological 153 controls on tropical forest photosynthesis will not only improve modeling of photosynthesis in 154 the tropics but also help assess the correct functional response to environmental variability.

\section{Materials and Methods}

2.1 Model evaluation tower site (with Fluxnet2015 ID of "BR-Sa1"; http://fluxnet.fluxdata.org/data/download-data/). 160 The k67 EC tower site $\left(54^{\circ} 58^{\prime} \mathrm{W}, 2^{\circ} 51^{\prime} \mathrm{S}\right)$ is located in the Tapajós National Forest, near 161 Santarém, Pará, Brazil. Tapajós is an evergreen tropical forest on a well-drained clay-soil plateau 162 (Rice et al., 2004), with a mean upper canopy height of $40 \mathrm{~m}$ (Hutyra et al., 2007). Mean 163 annual precipitation is $\sim 2000 \mathrm{~mm}$ year $^{-1}$ with a 5-month dry season (monthly precipitation $<$ 164 monthly evapotranspiration) from approximately mid-July to mid-December (Hutyra et al., 165 2007; Restrepo-Coupe et al., 2013). 
The k67 EC site included seven-full-year flux and meteorological measurements (years

167

168

169

170

$171\left(\mathrm{R}_{\mathrm{eco}}\right)$ and GPP following standard approaches (Hutyra et al., 2007; Restrepo-Coupe et al.,

172 2013): Reco, which was averaged within monthly bins from valid nighttime hourly NEE during

173 well-mixed periods ( $\mathrm{u}^{*}$ criterion: $\geq 0.22 \mathrm{~m} / \mathrm{s}$ ), was also used as an estimate of average monthly

174 daytime respiration, and GPP was estimated as -(NEE - Reco). We did not use a temperature

175 function to extrapolate nighttime NEE to daytime Reco, as is done at many higher latitude sites

176 (e.g. Reichstein et al., 2005), because nighttime temperature range within most months at k67 is

177 too small to constrain such a function (Hutyra et al., 2007). Also because Reco is composited by

178 the two components: (1) the heterotrophic component (which is expected to have higher values

179 in the daytime, due to higher temperature in the daytime than at night; Reichstein et al., 2005),

180

181

182

183

184

185

186

187

188 and (2) the autotrophic component, especially the part associated with foliar respiration (which is expected to have lower values in the daytime, due to light-inhibition of mitochondrial respiration in leaves; Heskel et al., 2013; Wehr et al., 2016), therefore, without the specific information about the relative contribution of these two components, we judged that our approach (using unmodified nighttime values as estimates for daytime Reco) was conservative - especially for a study of seasonality, for which potential errors in absolute value are less important.

In this study we used the reference GPP $\left(\mathrm{GPP}_{\text {ref }}\right)$ as our target variable and benchmark for model evaluation. GPP ref represents the $\mathrm{CO}_{2}$ assimilation of the canopy in the absence of environmental fluctuations and thus provides the capability to evaluate the phenological impact 
189 on canopy-scale photosynthesis independent of other sources of variation. EC-derived GPP ref 190 was calculated as the monthly average of all seven-year EC-derived GPP measurements under a 191 reference environmental condition, following Wu et al (2016a, 2017). The EC-derived GPP ref 192 here scales linearly with incident light-use-efficiency under the reference environment as used in $193 \mathrm{Wu}$ et al (2016a, 2017) (where it was called canopy-scale photosynthetic capacity). The 194 reference environment for $\mathrm{GPP}_{\text {ref }}$ was taken as narrow bins of each climatic driver: canopy-top 195 photosynthetically active radiation $\left(P A R_{0}\right)=1320 \pm 200 \mu \mathrm{mol} \mathrm{m} \mathrm{s}^{-1}$, diffuse light fraction=0.4 \pm 1960.1 , vapor pressure deficit $(\mathrm{VPD})=0.87 \pm 0.20 \mathrm{kPa}$, air-temperature $\left(\mathrm{T}_{\text {air }}\right)=28 \pm 1{ }^{\circ} \mathrm{C}$, and solar 197 zenith angle $(\mathrm{SZA})=30 \pm 5^{\circ}$, and $8.1 \%$ of all hourly EC-derived GPP measurements were 198 selected under the reference environment $(\sim 20$ measurements per month per year; almost equally 199 distributed across months). We used the seven-year mean annual cycle of monthly EC-derived $200 \mathrm{GPP}_{\text {ref }}$ as a benchmark for model validation. The same reference environment is also used for our 201 model simulation of canopy-scale GPP ref (see ”Model Framework" below).

202

2.2 Prescribed phenology

Three components of leaf phenology were examined in this study, including the quantity, the quality, and within-canopy variation in leaf turnover rates, all of which are tightly linked with 206 seasonal variability in leaf production, development and abscission within a tropical forest 207 canopy (Wu et al., 2016a,b; Lopes et al., 2016). Our prescribed, field-based leaf phenology data 208 at the k67 site are the same as those used in Wu et al (2016a).

(1) Field data of canopy LAI, litterfall LAI, and new leaf LAI. The mean annual cycle of 210 monthly canopy LAI (range: $5.35-6.15 \mathrm{~m}^{2} \mathrm{~m}^{-2}$ ) was derived from tower-mounted camera image 211 timeseries (Tetracam Agricultural Digital Camera, Tetracam, Inc., Gaomesville, FL; January 
2122010 to December 2011) using a camera-based tree inventory approach. For details about this 213 approach, please refer to supplementary materials section 5 and Figs. S5 and S8 in Wu et al 214 (2016a). The mean annual cycle of monthly litterfall LAI (range: $0.23-0.66 \mathrm{~m}^{2} \mathrm{~m}^{-2}$ ) was derived 215 by converting field observations of mass-based foliage litterfall (Mg biomass month ${ }^{-1} \mathrm{ha}^{-1}$; bi216 weekly measurements from 2001 to 2005; Brando et al., 2010) of the same site into area-based

217 litterfall LAI $\left(\mathrm{m}^{2} \mathrm{~m}^{-2}\right.$ per month), with the formula of Litterfall LAI = mass-based 218 Litterfall $\times$ SLA, applying a mean specific leaf area (SLA) of 0.816 ha $\mathrm{Mg}^{-1}$ biomass (Malhado et 219 al., 2009). The mean annual cycle of monthly new leaf LAI production (in $\mathrm{m}^{2} \mathrm{~m}^{-2}$ per month) 220 was estimated by using the formula of $\mathrm{dLAI} / \mathrm{dt}+$ litterfall LAI, where $\mathrm{dLAI} / \mathrm{dt}$ is the average 221 canopy LAI change in the two months centered around LAI of each month (Wu et al., 2016a).

(2) Field based leaf gas exchange measurements. Leaf level photosynthetic capacity, 223 represented by the apparent maximum carboxylation capacity of Rubisco standardized to a 224 reference temperature of $25^{\circ} \mathrm{C}\left(V_{\mathrm{cmax} 25}\right)$ (Bernacchi et al., 2013), was derived from standard leaf 225 gas exchange measurements of photosynthetic $\mathrm{CO}_{2}$ response curves $\left(A-\mathrm{C}_{\mathrm{i}}\right)$ for top-of-canopy 226 sunlit leaves of five canopy trees at the k67 site (species and structural information for leaf 227 samples are shown in Table S1; data are available from 228 http://datadryad.org/resource/doi:10.5061/dryad.8fb47; see supplementary materials in Wu et al, 2292016 a for more details on these data). Briefly, the trees we targeted for $A-C i$ curves represent the most abundant species that account for $\sim 24 \%$ of the local basal area (Pyle et al., 2008). Prior to 231 gas exchange measurements, branches (of $\sim 1 \mathrm{~m}$ length) were assessed using arborist climbing 232 methods, cut, then promptly but gently lowered to the ground with ropes, and re-cut under water 233 at least once within 15 minutes of the initial harvest. Gas exchange was typically measured for 234 leaves of each age category present on the branch. These sunlit leaves $(n=27)$ were initially 
235 classified into three age classes (Young, Mature, and Old) based on visual assessment of color,

236 size, rigidity, and bud scars (when present) (Chavana-Bryant et al., 2016), and then confirmed by

237 in-situ leaf tagging and associated photographic imaging of leaves at known ages (from 10 days

238 old up to 1 year old; see Wu et al., 2016b for more details). These leaf age classes roughly

239 correspond to a young age class (leaves of 1-2 months old), a mature age class (leaves of 3-5

240 months), and an old age class (leaves of $\geq 6$ months). Very young leaves (recent leaf burst; e.g.

241 Fig. S1 in $\mathrm{Wu}$ et al., 2016b) were too small, delicate, or logistically challenging for

242 photosynthesis measurements, therefore field derived leaf $V_{\mathrm{cmax} 25}$ of the young age class (which

243 corresponds to the young leaves of late stage, big enough for Licor measurements) was then

244 divided by two to provide an average across the distribution of the entire young age class. The

245 five-species mean ( \pm standard deviation) $V_{\mathrm{cmax} 25}$ for these top-of-canopy sunlit leaves of young,

246 mature, and old age classes were $6.8( \pm 1.4), 36.5( \pm 10.7)$, and $23.4( \pm 5.1) \mu \mathrm{mol} \mathrm{CO}_{2} \mathrm{~m}^{-2} \mathrm{~s}^{-1}$,

247 respectively.

248

(3) The mean seasonality of leaf age demographics and leaf quality. The quality 249 component of leaf phenology refers to per-area leaf photosynthetic capacity. At the canopy scale,

250 leaf quality can be approximated by the age-dependency of leaf photosynthetic capacity (shown 251 above) and the associated leaf age fraction (or leaf age-demography). Leaf age demographics 252 were approximated by a three-LAI-age-class demography model (Wu et al, 2016a), with the 253 inputs from mean annual cycles of monthly canopy LAI and new leaf LAI (calculated above).

254 The model-derived three LAI-age demographics include the LAI for a young age class (leaves of 255 1-2 months old, $L A I_{Y}$ ), a mature age class (leaves of 3-5 months, $L A I_{M}$ ), and an old age class 256 (leaves of $\geq 6$ months, $L A I_{O}$; see Fig. 1), with the two optimized model parameters from Wu et al 257 (2016a) which define leaf residence time at young and mature age classes respectively. The 
258 reason we use these optimized parameters here is because these parameters were consistent with 259 our field observations of leaf aging processes (Chavana-Bryant et al., 2016; Wu et al., 2016b), as 260 well as the roughly similar time interval of mature and old leaf age classes for field-based leaf 261 gas exchange measurements.

262

263 ontogeny model as below (Wu et al, 2016a).

264

$$
\text { Lquality }=\frac{V_{c \max , Y} \times L A I_{Y}+V_{c \max , M} \times L A I_{M}+V_{c \max , O} \times L A I_{O}}{L A I_{Y}+L A I_{M}+L A I_{O}}
$$

265 Where Lquality is leaf quality, which represents age composition weighted leaf photosynthetic 266 capacity, and $V_{\mathrm{cmax}, \mathrm{Y}}, V_{\mathrm{cmax}, \mathrm{M}}$, and $V_{\mathrm{cmax}, \mathrm{O}}$ represent leaf level $V_{\mathrm{cmax}}$ at young, mature and old age 267 classes respectively.

2.3 Model framework

2.3.1 TBM-type canopy photosynthesis models (DF1997 and ML)

272 canopy as a big leaf of the two fractions (sun versus shade), are commonly used in many TBMs, 273 e.g. Community Land Model version 4.5 (CLM4.5; Oleson et al., 2013) and the Joint UK Land 274 Environmental Simulator version 4.5 (JULES4.5; Best et al., 2011; Clark et al., 2011; Harper et 275 al., 2016). Canopy photosynthesis is usually represented in these formulations by the two 276 processes: a leaf scale mechanistic photosynthesis model and a leaf-canopy scaling relationship, 277 which represents the whole forest canopy as sunlit and shade fractions using approaches such as 278 dePury and Farquhar (1997; DF1997) or a multi-layer approach (Drewry et al., 2010; ML). 279 These processes are described in detail as below. 
(1) A leaf scale mechanistic photosynthesis model. Here we couple a mechanistic FvCB

281

282

283

284

285

286

287

288

289

290

291

292

293

294

295

296

297

298

299

300

301

302 based photosynthesis model with a stomatal conductance scheme (Medlyn et al., 2011; Lin et al., 2015) to simulate the leaf level photosynthesis response to the variability in both biotic (e.g. $\mathrm{V}_{\mathrm{cmax} 25}$ and $\mathrm{J}_{\max 25}$ ) and climatic (e.g. PAR, temperature and VPD) factors (details in Table S2). The Medlyn-type stomatal conductance model was selected because leaves/stomata respond to VPD rather than relative humidity. Therefore, the Medlyn-type stomatal conductance model will likely capture projected increases in VPD better than other alternatives (Rogers et al., 2017). The only prescribed parameter of this stomatal conductance model is the stomatal slope, and here we used the value of 3.77 based on a recent meta-data analysis for tropical rainforest trees (Lin et al., 2015). Additionally, we refer to Lloyd \& Farquhar (2008) and Bernacchi et al (2013) to describe the temperature effect on leaf photosynthesis. As such, this photosynthesis model has the capability to simulate the leaf level photosynthetic response to the current environmental variability, but also to the changing environmental drivers associated with global change (i.e. rising $\mathrm{CO}_{2}$ concentration, temperature and VPD).

(2) The leaf to canopy scaling relationship represented by the DF1997 model. DF1997 simulates canopy photosynthesis as the sum of the photosynthetic rate contributed by the sunlit fraction $\left(G P P_{\text {sun }}\right)$ and the shade fraction $\left(G P P_{\text {shade }}\right)$ of a forest canopy respectively (eqn. 2$)$.

$$
G P P=G P P_{\text {sun }}+G P P_{\text {shade }}
$$

The DF1997 model is operated by firstly determining the LAI, $V_{\mathrm{cmax}}$ and absorbed PAR for each canopy fraction, and then applying leaf level photosynthesis model (as above) to simulate the photosynthesis to each canopy fraction. Canopy total LAI $\left(L A I_{t o t}\right)$ is partitioned into the sunlit fraction $\left(L A I_{\text {sun }}\right)$ and the shade fraction $\left(L A I_{\text {shade }}\right)$, following Beer's law (eqns. 3-4; dePury \& Farquhar, 1997; Chen et al., 1999; Ryu et al., 2011): 


$$
L A I_{\text {sun }}=\frac{1-\exp \left(-\frac{k \times \Omega \times L A I_{t o t}}{\cos (S Z A)}\right)}{k / \cos (S Z A)}
$$

$$
L A I_{\text {shade }}=L A I_{\text {tot }}-L A I_{\text {sun }}
$$

where $\mathrm{k}(=0.5)$ is the extinction coefficient, and $\Omega$ is the clumping index; $\Omega=0.66$ for tropical evergreen forest (He et al., 2012) was used in this study.

DF1997 also partitions the canopy integrated $V_{\text {cmax }}\left(V_{\text {cmax,tot }}\right)$ into the sunlit fraction $\left(V_{\text {cmax,sun }}\right)$ and the shade fraction $\left(V_{\text {cmax,shade }}\right)$ (see Table S3). Here we assumed that $V_{\text {cmax }}$ declines exponentially within the canopy following Lloyd et al (2010) (see eqns. 5-6 below; Fig. 2).

$$
\begin{aligned}
& V_{c \max , i}=V_{c \max , 0} \times \exp \left(-k_{n} \times L A I_{i}\right) \\
& k_{n}=\exp \left(0.00963 \times V_{c \text { max }, 0}-2.43\right)
\end{aligned}
$$

where $V_{c \max , 0}$ is the $V_{\text {cmax }}$ of leaves at the top of the canopy; and $k_{n}$ describes the exponential decline of $V_{\text {cmax }}$ against the given accumulated LAI from the top of the canopy $\left(L A I_{i}\right)$. By tracking PAR at the top of the canopy $\left(P A R_{0}\right)$, which is the sum of direct beam $\left(P A R_{b, 0}\right)$ and diffuse radiation $\left(P A R_{d, 0}\right)$ in the visible spectrum (i.e. $\left.400-700 \mathrm{~nm}\right)$, DF1997 calculates its canopy absorbance by the sunlit fraction $\left(P A R_{\text {sun }}\right)$ and by the shade fraction $\left(P A R_{\text {shade }}\right)$, using Beer's law and Seller's (1987) two-stream approximation for canopy radiative transfer (dePury \& Farquhar, 1997; Ryu et al., 2011; Tables S4-S5).

To facilitate the simulation of photosynthetic seasonality with DF1997, we prescribed top-of-canopy $V_{\mathrm{cmax}, 0}($ in eqn. 5), i.e. Lquality (eqn. 1), while assuming that vertical changes in $V_{\text {cmax }}$ within a forest canopy follow a fixed exponential decline rate (as described by eqns. 5-6). The complete equation set for the DF1997 model is provided in Tables S2-S5.

(3) The leaf-canopy scaling relationship represented by the multi-layer model. ML is an alternative way to scale leaf-level function and simulate canopy photosynthesis. ML explicitly 
325 resolves direct and diffuse radiation for sunlit and shade canopy fractions at each canopy layer

326

327

328

329

330

331

332 the reference environment. using Seller's (1987) two-stream approximation for canopy radiative transfer. The number of canopy layers is prescribed as $\mathrm{N}$, where initial results from a model sensitivity showed that GPP was insensitive to $\mathrm{N} \geq 15$ (Fig. $\mathrm{S} 1$ ). We thus used $\mathrm{N}=15$ for the following simulations. In addition, we calculated the LAI of the sunlit $\left(L A I_{\text {sun, }, i}\right)$ and the shaded $\left(L A I_{\text {shade, }, i}\right)$ fractions for each canopy layer $i(\mathrm{i}=1,2, \ldots, \mathrm{N})$, and their corresponding per-area radiation absorbed by the sunlit fraction $\left(P A R_{\text {sun }, i}\right)$ and the shade fraction $\left(P A R_{\text {shade }, i}\right)$. Last, ML calculated the $V_{\text {cmax }}$ of each canopy layer $\left(V_{c m a x, i}\right)$ also using eqns. 5-6.

The leaf level photosynthesis model was then used to calculate the photosynthesis rate of each canopy fraction for given layer $i$ : per-area photosynthesis rate for the sunlit $\left(G P P_{\text {sun,area, } i}\right)$ and the shade $\left(G P P_{\text {shade, area }, i}\right)$. The cumulative canopy photosynthesis rate was thus equal to the sum of area weighted photosynthesis rate of each layer:

$$
G P P=\sum_{i=1}^{N}\left(G P P_{\text {sun }, \text { area }, i} \times L A I_{\text {sun }, i}+G P P_{\text {shade }, \text { area }, i} \times L A I_{\text {shade }, i}\right)
$$

To facilitate the simulation of photosynthetic seasonality with ML, we also prescribed top-of-canopy $V_{\mathrm{cmax}, 0}($ in eqn. 5), i.e. Lquality (eqn. 1).

It is important to note that the models (DF1997 and ML) presented here can simulate leaf phenology effects of both quantity and quality components; however, none of these models accounted for within-canopy phenological variation, and assumed a constant leaf turnover (flushing and abscission) rate throughout the canopy. Additionally, in our model simulation, we assume that leaf temperature and VPD for the sunlit and shade canopy fractions are the same as 
347 348

350

351

352 353

2.3.2 Modified TBM representation of canopy photosynthesis to allow for within-canopy phenological variation (a two-fraction leaf, two-layer canopy model)

Many field-based studies have indicated that leaf longevity could vary greatly depending on the growth environments (e.g. Wright et al., 2006; Wu et al., 2016b), with understory leaves displaying longer leaf longevity than upper canopy leaves (Lowman, 1992; Miyaji et al., 1997; Reich et al., 2004). This suggests that the leaf turnover rate in the upper canopy should be faster than that in the lower canopy and understory. However, the within-canopy phenological variation has not been explicitly accounted for until now. To accomplish this, we modified the ML model framework (via addition of a second, lower canopy layer) to allow explicit representation of within-canopy variation in leaf turnover, in addition to the sun andshade fractions that already allow for within-canopy physiological variation.

In this new model, we divided a forest canopy into the two layers: (1) the upper canopy layer with the cumulative LAI from 0 (top-of-canopy) to $2.5 \mathrm{~m}^{2} \mathrm{~m}^{-2}$, and (2) the lower canopy layer including the remainder of the canopy. Both layers are assumed to have the same phenological pattern and timing, but the amount of leaf flush and litterfall that drives phenology is differentially allocated between them. This allocation between layers is specified by ftop, the fraction of observed leaf turnover (including leaf drop and flush) across the whole forest canopy attributed to leaves in the upper canopy layer, e.g. when ftop $=0.7,70 \%$ of observed forest canopy leaf turnover (and associated amplitude of the LAI and Lquality variables) is attributed to the upper canopy layer and $30 \%$ to the lower canopy layer; under this case, the ratio of leaf turnover rate between upper canopy leaves and lower canopy leaves can be calculated as (ftop/LAI_up) $/((1$-ftop $) /$ LAI_low $)=2.8$, where ftop=0.7, LAI_up (or the average LAI for the upper canopy layer) $=2.5 \mathrm{~m}^{2} \mathrm{~m}^{-2}$, and LAI_low (or the average LAI for lower canopy layer) $=3 \mathrm{~m}^{2}$ 
$370 \mathrm{~m}^{-2}$. Since leaf longevity is an inverse of leaf turnover rate, therefore the leaf longevity for the

371 lower canopy leaves is around 2.8 times longer than the upper canopy leaves when ftop=0.7. Our

372 differentiation of these two canopy layers (upper and lower) at the LAI cutoff of $2.5 \mathrm{~m}^{2} \mathrm{~m}^{-2}$ for

373 the upper canopy is slightly arbitrary, but sensitivity analysis showed that our modeling results

374 were largely insensitive to the LAI cutoff and exhibited only minor variation when LAI 375 increased from 2 to $3 \mathrm{~m}^{2} \mathrm{~m}^{-2}$ (Fig. S2).

376

$377 \quad 2.4$ Model experiments

378 We used our proposed two-fraction leaf, two-layer canopy model as the main modeling 379 testbed for assessing the effect of different phenological components on modeled canopy 380 photosynthetic seasonality. This is because previous studies (e.g. dePury and Farquhar, 1997; 381 Bonan et al., 2012) demonstrate that DF1997 and ML can simulate almost identical GPP fluxes 382 at the canopy scale (which is also confirmed by our Fig. S3), and also because our proposed two383 fraction leaf, two-layer canopy model here is identical to ML when no within-canopy 384 phenological variation is considered but also enables to examine the effect of within-canopy 385 phenological variation by varying ftop. First, we ran the model parameterized by all three 386 components, aiming to explore how well the model with all phenological mechanisms can 387 capture EC-derived $\mathrm{GPP}_{\text {ref }}$ seasonality. The model inputs for these phenological components 388 include: (1) the leaf quantity based on field measurements of the mean annual cycle of monthly 389 LAI, (2) the leaf quality based on field-derived seasonality of Lquality (as calculated by eqn. 1, 390 weighted by field-measured age dependency of $\mathrm{V}_{\mathrm{cmax} 25}$ and field-derived leaf age demographics), 391 and (3) the within-canopy phenological variation, by assuming leaves of lower canopy layer had 3922.8 times longer leaf longevity compared with that of upper canopy layer (or ftop=0.7), which is 
393 consistent with the literature (e.g. Lowman, 1992; Miyaji et al., 1997; Reich et al., 2004). We

394 also ran the models under two additional scenarios, aiming to explore the relative role of each

395 phenological component on modeled photosynthetic seasonality, with that (1) the model is

396 parameterized with the observed annual cycle of leaf quantity alone, while assuming neither

397 within-canopy variation in leaf longevity nor seasonal variation in leaf quality, and that (2) the

398 model is parameterized with the observed phenological cycles of leaf quantity and quality, while

399 assuming a constant leaf turnover rate throughout the canopy. To further elucidate the

400 mechanisms by which each phenological component regulates canopy photosynthetic

401 seasonality, we also evaluated the $\mathrm{GPP}_{\text {ref }}$ sensitivity of the sunlit canopy fraction and the shade

402 canopy fraction to the seasonal variation in leaf phenology (quantity and quality) and within-

403 canopy variation in leaf longevity (by varying ftop from 0 to 1.0 with the increment of 0.1 )

404 respectively.

405

406 3. Results

$407 \quad 3.1$ Modeled GPP $_{\text {ref }}$ seasonality parameterized by differential leaf phenological mechanisms

408 We used the two-fraction leaf, two-layer canopy model to explore how including model

409 representation of the three different phenological components affected the ability of the models

410 to simulate the canopy scale photosynthetic seasonality, as compared with EC-derived GPP ${ }_{\text {ref. }}$

411 Our results show that the model parameterized by all three phenological components (i.e.

412 quantity, quality and within-canopy phenological variation) was best able to capture EC-derived

413 photosynthetic seasonality (Fig. 3 and Table 1).

414 The seven-year mean annual cycle of EC-derived GPP ${ }_{\text {ref }}$ at the Tapajós k67 site showed 415 an initial decline in the late wet season, and then an increase in the dry season (Fig. 3). The 
416 models parameterized by leaf quantity alone or parameterized by both leaf quantity and quality

417 displayed good agreement with the timing of EC-derived GPP ${ }_{\text {ref }}$ seasonality, but missed the

418 depth or relative magnitude of $\mathrm{GPP}_{\text {ref }}$ seasonality: leaf quantity phenology alone explained only

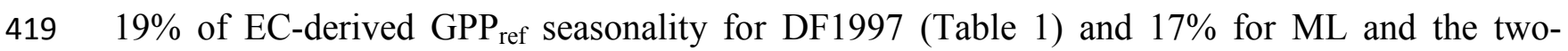
420 fraction leaf, two-layer canopy model (Table 1 and Fig. 3a); the modeled GPP ref with both leaf 421 quantity and quality (but no within-canopy phenological variation) explained $\sim 80 \%$ of EC-

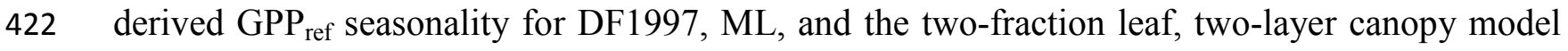
423 (Table 1 and Fig. 3b). The modeled GPP ref using the two-fraction leaf, two-layer canopy model 424 with all three phenological components displayed the strongest agreement with the seasonal 425 variability of EC-derived GPP ref in both timing and relative magnitude $\left(\mathrm{R}^{2}=0.90\right.$; Table 1 and 426 Fig. 3c).

427

$428 \quad 3.2$ Differential photosynthetic sensitivity to seasonal variation in leaf phenology between the 429 sunlit canopy fraction and the shade canopy fraction

To better understand the mechanisms that underlie canopy-scale photosynthetic 431 seasonality, we examined the photosynthetic sensitivity of the sunlit canopy fraction and the 432 shade canopy fraction to seasonal variation in leaf phenology (quantity and quality). We 433 theorized that the seasonal variation in $\mathrm{GPP}_{\text {ref }}$ is driven by changes in both canopy absorbed PAR 434 (affecting RuBP regeneration limited photosynthesis in the FvCB model) and canopy integrated $435 V_{\text {cmax }}$ (affecting Rubisco limited photosynthesis in the FvCB model). Fig. 4 summarizes our 436 model diagnosis of these two pathways and their respective influence on modeled $\mathrm{GPP}_{\text {ref }}$ 437 seasonality. 
First we examined the seasonal dynamics of canopy absorbed PAR under reference

439

440

441

442

443

444

445

446

447

448

449

450

451

452

453

454

455

456

457

458

459

460 environmental conditions (absolute value in Fig. 4a and relative value in Fig. S4). Our simulations showed that the PAR absorbed by the sunlit canopy fraction $\left(P A R_{\text {sun }}\right)$, the shade canopy fraction $\left(P A R_{\text {shade }}\right)$, and the entire canopy $\left(P A R_{\text {sun }}+P A R_{\text {shade }}\right)$ all showed consistently low seasonal variability (<6\%; Fig. 4a and Fig. S4), despite modest seasonal variability in leaf quantity ( $\sim 12 \%$; Fig. $4 \mathrm{~b})$. This is likely because tropical evergreen forests display consistently high leaf quantity over the annual cycle (e.g. LAI range: $5.35-6.15 \mathrm{~m}^{2} \mathrm{~m}^{-2}$ at the $\mathrm{k} 67 \mathrm{site}$ ), and as such annual FAPAR is typically at or near saturation.

We then investigated the seasonal dynamics of canopy $V_{c m a x}$, which is the integrated sum of leaf level $V_{c \max }$ weighted by the total LAI attributed to the sunlit fraction and the shade fraction respectively (see eqns 3-5). Focusing first on the sunlit fraction, Fig. 4b highlights that the $L A I_{\text {sun }}$ is generally stable $\left(\sim 1.5 \mathrm{~m}^{2} \mathrm{~m}^{-2}\right)$ through the annual cycle, despite the observed modest seasonality in total canopy leaf quantity $\left(L A I_{\text {tot }}=L A I_{\text {sun }}+L A I_{\text {shade }}\right)$. As a consequence, the observed higher seasonal variability $(\sim 20 \%)$ in $V_{\text {cmax, sun }}$ (Fig. 4c) is primarily driven by leaf quality, which is associated with seasonal variation in leaf age demographics (Fig. 1 and eqn. 1). In addition, our results indicated that the higher seasonal variability $(\sim 25 \%)$ in $V_{\text {cmax, shade }}$ (Fig. $4 \mathrm{c}$ ) is a consequence of seasonal variability in both $L A I_{\text {shade }}$ (Fig. 4b) and leaf age demographics (Fig. 1 and eqn. 1).

Finally, we assessed the seasonal variability in $\mathrm{GPP}_{\text {ref }}$ as the joint response to the above two dynamics: canopy absorbed PAR and $V_{\text {cmax }}$. We used the FvCB model to calculate the GPP ref of both fractions (sun vs. shade). Sensitivity analysis of the FvCB model (Fig. S5) showed that the canopy integrated absorbed PAR and canopy integrated $V_{\text {cmax }}$ jointly regulated GPP $\mathrm{ref}_{\text {, with }}$ canopy integrated $V_{\text {cmax }}$ dominating the $\mathrm{GPP}_{\text {ref }}$ response under high light condition (i.e. 
461 PAR $>800 \mu \mathrm{mol} \mathrm{m}^{-2} \mathrm{~s}^{-1}$ ) while canopy integrated absorbed PAR dominated GPP $\mathrm{ref}_{\text {response under }}$ 462 low light condition (i.e. PAR $<400 \mu \mathrm{mol} \mathrm{m} \mathrm{m}^{-2}$ ). Given that the sunlit fraction could consistently 463 capture sufficient PAR to photosaturate photosynthesis $\left(\sim 860 \mu \mathrm{mol} \mathrm{m} \mathrm{m}^{-2}\right.$; Fig. 4a) over the 464 annual cycle, the seasonal variability in $\mathrm{GPP}_{\text {ref, sun }}$ closely tracked the seasonality of $V_{\text {cmax,sun }}$ 465 (Figs. 4c,d), which is mostly determined by the phenology of leaf quality (Figs. 4b,c). On the 466 other hand, since the shade fraction typically receives sub-saturating light $\left(\sim 300 \mu \mathrm{mol} \mathrm{m}^{-2} \mathrm{~s}^{-1}\right.$; 467 Fig. 4a) over the annual cycle, GPP ref, shade is primarily limited by the capacity for RuBP 468 regeneration (Fig. S5). As a result, modeled GPP ref, shade seasonality is small ( 7\%; Fig. S6), 469 which is comparable with the relative seasonal change in $P A R_{\text {shade }}(\sim 6 \%$; Fig. S4), but far less 470 than the relative seasonality in $V_{\text {cmax, shade }}(25 \%$; Fig. $4 \mathrm{c})$. The canopy total GPP ref thus showed an 471 intermediate seasonal variation, with the relative magnitude of annual change falling in between 472 that of the two fractions (absolute value in Fig. 4d and relative value in Fig. S6).

473

3.3 Model sensitivity of canopy photosynthesis to within-canopy phenological variations

Finally, we used the two-fraction leaf, two-layer canopy model to explore the extent to 476 which within-canopy phenological variations could affect modeled photosynthetic seasonality.

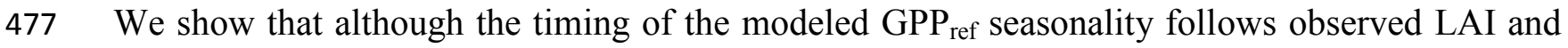
478 LAI-age-demography (Fig. 1) and was independent of within-canopy phenological variation (i.e. 479 ftop), the relative magnitude of the modeled GPP ${ }_{\text {ref }}$ seasonality is highly sensitive to ftop (Fig. 480 5a). As ftop increases (more leaf turnover is partitioned to the upper canopy), the relative 481 magnitude of modeled $\mathrm{GPP}_{\text {ref }}$ seasonality increases (Fig. 5a). Meanwhile, the correlation 482 between modeled and EC-derived $\mathrm{GPP}_{\text {ref }}$ seasonality also increases with ftop and reaches near 483 saturation when ftop $\geq 0.7\left(\mathrm{R}^{2}=0.90\right.$; Fig. 5b). The underlying reason is associated with the 
484 differential photosynthetic sensitivity to leaf quality allocated to the two canopy layers (upper vs.

485 lower): as shown in Fig. 4, only the photosynthetic rate of the sunlit fraction (mostly occupied in 486 the upper canopy layer) is predominantly Rubisco limited and therefore, the photosynthetic rate 487 of the upper canopy layer shows high sensitivity to leaf quality.

488

489

490

491

492

493

494

495

496

497

498

499

500

501

502

503

504

505

506

\section{Discussion}

Accurate model representation of the effects of leaf phenology on ecosystem photosynthesis is a critical need for TBMs in general (Richardson et al., 2012) and is essential, necessary first step for capturing the timing and magnitude of seasonal variation in tropical forest carbon fluxes (Restrepo-Coupe et al., 2013, 2017; Fu et al., 2013; Christoffersen et al., 2014; Wu et al., 2016a). Here we developed a parsimonious approach to effectively couple the effects of leaf phenology (i.e. quantity, quality and within-canopy variation) to the FvCB model for simulating canopy-level photosynthetic seasonality. Our approach could be parameterized and adopted within TBMs where it would enable improved representation and projection of the response of tropical evergreen forest photosynthesis to global change.

Our results demonstrated that the proposed model (two-fraction leaf, two-layer canopy) could effectively simulate EC-derived photosynthetic seasonality, only if the quality component of leaf phenology was incorporated (Fig. 3 and Table 1). This is also consistent with previous field-based remote sensing studies (Doughty \& Goulden, 2008; Brando et al., 2010; Lopes et al., 2016; Saleska et al., 2016), which highlight that variation in photosynthetic efficiency and the spectral reflectance properties of leaves (Roberts et al., 1998; Chavana-Bryant et al., 2016; Wu et al., 2016a,b) may significantly contribute to explaining the satellite-detected dry season "green-up" in tropical evergreen forests. In addition, our finding supports previous work which 
507 showed that model representation of photosynthetic seasonality could be improved by tuning 508 model parameters to allow for seasonal variation in photosynthetic capacity, i.e. leaf quality 509 (Kim et al., 2012; de Weirt et al., 2012).

510 Although the models with different leaf phenological components were all able to 511 simulate the seasonal photosynthetic trend, the relative magnitude of modeled GPP ${ }_{\text {ref }}$ seasonality 512 varied strongly across the models (Fig. 3). The approach of incorporating all phenological 513 components (i.e. quantity, quality, and within-canopy variation) displayed the strongest 514 agreement with local EC-derived $\mathrm{GPP}_{\text {ref, }}$ while the approaches incorporating only part of the 515 three phenological components (e.g. leaf quantity alone in Fig. 3a and leaf quantity and quality 516 alone in Fig. 3b) only explained around half or less of the observed relative annual change 517 magnitude. These differences in model performance can be attributed to differential 518 photosynthetic sensitivity of the sunlit canopy fraction and the shade canopy fraction to seasonal 519 variation in leaf quantity, quality and within-canopy phenological variation, explained as below: Leaf quantity. Our results show that there is only a weak effect of the quantity component

521 of leaf phenology on $\mathrm{GPP}_{\text {ref }}($ Table 1). This is because tropical evergreen forests consistently 522 have high leaf quantity throughout the annual cycle (Myneni et al., 1997; Doughty \& Goulden, 523 2008; Brando et al., 2010; Morton et al., 2014; Bi et al., 2015; Lopes et al., 2016; Wu et al., 524 2016a), and therefore the observed small seasonal changes in leaf quantity had little impact on 525 FAPAR seasonality (Fig. 4a and Fig. S4), and thus had little impact on GPP ref seasonality.

526 Leaf quality. Our results show that the phenology of leaf quality is one of the dominant 527 drivers of canopy photosynthetic seasonality in tropical evergreen forests (Table 1), confirming 528 recent work (Wu et al., 2016a). Using an FvCB-type canopy photosynthesis model (i.e. two529 fraction leaf, two-layer canopy model), we demonstrate that both light absorption and canopy 
530 integrated $V_{\text {cmax }}$ regulate canopy-scale photosynthesis rate (Fig. S5). However, only the upper, 531 sunlit canopy fraction with sufficient light availability and absorption are limited by Rubsico (i.e. 532 are light saturated) and show sensitivity to seasonal variation in leaf quality (i.e. $V_{\text {cmax }}$; Figs. 4 , 533 S5 and S6). In contrast, the shaded canopy fraction is predominantly limited by light and not by 534 photosynthetic capacity, and consequently, increasing photosynthetic capacity in the shaded 535 canopy fraction has little to no impact on the modeled $\mathrm{GPP}_{\text {ref. }}$ In other words, our results confirm 536 the differential photosynthetic sensitivity to leaf quality between the sunlit and shade canopy 537 fractions. Our finding is thus not consistent with the assumption made by Doughty \& Goulden 538 (2008), who assumed constant photosynthetic rates of the sunlit and shade canopy fractions with 539 a single scalar to account for seasonal variation in leaf quality, and may explain why the 540 approach of Doughty \& Goulden (2008) overestimates the leaf quality effect for the shade 541 canopy fraction.

542 Within-canopy phenological variation. Differential photosynthetic sensitivity of the sunlit 543 and shade canopy fractions to leaf quality (as shown in Fig. 4) suggests that the return on 544 investment for a new leaf is far greater if that leaf is flushed in the upper, sunlit canopy than in 545 the shade, which was subsequently confirmed by our model sensitivity analysis of ftop (Fig. 5). 546 This model sensitivity analysis demonstrated that by allowing for differential leaf turnover rates 547 within the canopy, especially when attributing the majority of leaf turnover to the upper canopy, 548 our model (two-fraction leaf, two-layer canopy) could markedly improve the model 549 representation of photosynthetic seasonality (Figs. 3, 5). Importantly, our prescribed higher leaf 550 turnover rate in the upper canopy (i.e. ftop $=0.7$ ) is also consistent with field-based studies in the 551 tropics which show that the longevity of upper canopy leaves is markedly shorter than that of 552 lower canopy leaves (Lowman, 1992; Miyaji et al., 1997; Reich et al., 2004). 
Our analysis of the two-fraction leaf, two-layer canopy model further show that when the

554

555

556

557

558

559

560

561

562

563

564

565

566

567

568

569

570

571 572 here.

573

574

575 majority of leaf turnover is allocated to the upper canopy, the whole forest tends to become more Rubisco-limited and thus approaches a simpler one-layer big-leaf assumption, such as the model presented in $\mathrm{Wu}$ et al (2016a). This explains why the simple model of Wu et al (2016a), which does not contain explicit representation of within-canopy physiological and phenological variation, still captured the seasonal cycle of $\mathrm{GPP}_{\text {ref }}$ in tropical evergreen forests. The approach of Wu et al (2016a), which is based on empirical relationships, is a valuable approach for broadscale remotely sensed monitoring of tropical forest carbon cycling but lacks the capacity to project tropical forest responses under future climates and global change. Thus a light-use efficiency approach (e.g. Wu et al., 2016a) is not as valuable for use within TBMs that typically utilize the $\mathrm{FvCB}$ formulation of photosynthesis to simulate leaf and canopy photosynthesis (Rogers et al., 2017). Since TBMs need to project the response of photosynthesis to rising $\mathrm{CO}_{2}$, temperature, VPD and drought, they require more sophisticated approaches where key model inputs, such as $V_{c m a x}$, may be derived from trait databases, remote sensing, or internally generated (i.e. prognostic) allowing coupling to biogeochemical processes (e.g. Fisher et al., 2015; Serbin et al., 2015; Ali et al., 2016). Therefore, to accurately represent canopy photosynthetic processes in tropical forests under a changing climate we advocate the use of the approach outlined here, i.e. the two-fraction leaf, two-layer canopy model coupled to an FvCB formulation with model representation of the three components of leaf phenology we identify

Our work also highlights three important directions for future advances in model representation of tropical evergreen forest photosynthesis. First, to minimize additional sources of uncertainty when exploring approaches for the modeling of tropical forest photosynthetic 
576 seasonality we utilized observed leaf phenology (e.g. Fig. 1). However, the ultimate mechanisms

577 that regulate seasonal variation in both tropical leaf quantity and quality are still largely 578 unknown. An improved and prognostic understanding and model representation of the 579 mechanisms that drive seasonal and inter-annual changes in leaf quantity and quality, i.e. the 580 drivers of broader-scale (i.e. regional and global) tropical evergreen forest phenology, will be a 581 key component in new models that seek to improve projections of carbon dynamics and potential 582 climate feedbacks in the tropics (Wu et al., 2016a).

Second, our demonstration of the importance of leaf phenology effects on tropical forest 584

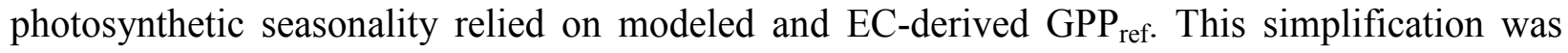
585 essential to enable us to elucidate fundamental mechanisms connecting annual patterns of leaf 586 phenology with physiology, but is not appropriate when simulating forest responses to climate 587 over time or in response to climatic perturbations. Since canopy photosynthesis is jointly 588 determined by extrinsic environmental variability and changes in intrinsic photosynthetic 589 machinery (Farquhar et al., 1980; Collatz et al., 1991; Sellers et al., 1992; dePury \& Farquhar, 590 1997; Baldocchi \& Amthor, 2001; Dai et al., 2003; Medvigy et al., 2009; Wu et al., 2016a; 591 Rogers et al., 2017), there is a great need to improve our understanding and model representation 592 of the fundamental physiological responses to environmental variability, particularly rising 593 atmospheric $\mathrm{CO}_{2}$ concentration, temperature, VPD and changes in precipitation, but also light 594 capture and utilization by the forest canopy (Rogers et al., 2017). It will be critical to link 595 advances in understanding of leaf phenology and physiology in future TBMs, particularly in 596 tropical evergreen forests.

Finally, our study also highlights that one of the most practical challenges limiting studies 598 in the tropics is the limited availability of observations (Schimel et al., 2015). For example, there 
599 is very little information available on the within-canopy (i.e. light-dependent vs. height600 dependent) and seasonal (i.e. continuous, age-dependency) variation in leaf physiology, 601 phenology, biochemical traits, and optical properties in the tropics (e.g. Kitajima et al., 1997b; 602 Chavana-Bryant et al., 2016; Wu et al., 2016b); even less is known about the spatial 603 heterogeneity in the relationship among photosynthetic capacity, leaf traits, canopy structure, 604 phenology, and climate across broader-scale (i.e. regional and global) tropical forests (e.g. 605 Kumagai et al., 2006; Kenzo et al., 2015; Wu et al., 2016b). As a consequence, some important 606 physiological mechanisms might be underrepresented in current models. For example, the study 607 presented by Kitajima et al (1997b) showed that leaf level Vcmax (at mature age class) for the 608 same tropical tree species can vary depends on the timing (i.e. wet or dry season) when leaves 609 are produced. This approach, also known as seasonal leaf phenotypes, suggested that leaf level 610 photosynthetic capacity should be modeled as a function of the timing when leaves are produced, 611 in addition to leaf age which has been explored in this paper. Our model framework has 612 sufficient flexibility to incorporate this additional component of photosynthetic seasonality, but 613 would require extensive field data and subsequent model evaluation to validate our approach.

\section{Acknowledgements:}

616 This work was supported by the Next-Generation Ecosystem Experiments-Tropics project 617 supported by the U.S. DOE, Office of Science, Office of Biological and Environmental Research 618 and through contract \#DE-SC0012704 to Brookhaven National Laboratory. We also thank Drs. 619 Youngryel Ryu and Chongya Jiang for sharing their code of the dePury \& Farquhar (1997) 620 model, which formed the initial base for our further coding development in this study. We also 
621 thank three anonymous reviewers for their constructive comments to improve the scientific rigor

622 and clarity of the manuscript.

623

624

\section{Author Contributions:}

625

J.W., A.R., S.P.S., and X.X. designed the research. J.W. and S.P.S. developed the Matlab and R

626 codes of canopy photosynthesis model. J.W. performed the data analysis. J.W. drafted the

627

628

629

630

631

632

633

634

635

636

637

638

639

640

641

642

643

644

645

646

647

648

649

650

651

652 manuscript, and A.R., S.P.S., S.R.S, X.X., L.P.A., M.C., and M.R. contributed to writing the final version.

\section{References}

Ali AA, Xu C, Rogers A, et al. (2016) A global scale mechanistic model of photosynthetic capacity (LUNA V1. 0). Geoscientific Model Development, 9, 587-606.

Aragão LEOC, Poulter B, Barlow JB, et al. (2014) Environmental change and the carbon balance of Amazonian forests. Biological Reviews, 89, 913-931.

Augspurger CK, Cheeseman JM, Salk CF (2005) Light gains and physiological capacity of understorey woody plants during phenological avoidance of canopy shade. Functional Ecology, 19, 537-546.

Baldocchi DD, Amthor JS (2001) Canopy Photosynthesis: History. In: Terrestrial global productivity (eds Roy J, Saugier B, Mooney HA), pp.9-31. Academic Press, Waltham, MA

Baker IT, Prihodko L, Denning AS, et al. (2008) Seasonal drought stress in the Amazon: Reconciling models and observations. Journal of Geophysical Research: Biogeosciences, 113, G00B01, doi: 10.1029/2007JG000644

Bernacchi CJ, Bagley JE, Serbin SP, et al. (2013) Modelling C3 photosynthesis from the chloroplast to the ecosystem. Plant, cell \& environment, 36, 1641-1657.

Best MJ, Pryor M, Clark DB, et al. (2011) The Joint UK Land Environment Simulator (JULES), model description-Part 1: energy and water fluxes. Geoscientific Model Development, 4, 677-699.

Bi J, Knvazikhin Y, Choi S, et al. (2015) Sunlight mediated seasonality in canopy structure and photosynthetic activity of Amazonian rainforests. Environmental Research Letters, 10, 064014, doi:10.1088/1748-9326/10/6/064014. 
Bonan GB, Oleson KW, Fisher RA, Lasslop G, Reichstein M. (2012) Reconciling leaf physiological traits and canopy flux data: Use of the TRY and FLUXNET databases in the Community Land Model version 4. Journal of Geophysical Research: Biogeosciences, 117, G02026, doi:10.1029/2011JG001913.

Bradley AV, Gerard FF, Barbier N, et al, (2011). Relationships between phenology, radiation and precipitation in the Amazon region. Global Change Biology, 17, 2245-2260.

Brando PM, Goetz SJ, Baccini A, et al. (2010) Seasonal and interannual variability of climate and vegetation indices across the Amazon. Proceedings of the National Academy of Sciences of the United States of America, 107, 14685-14690.

Chavana-Bryant C, Malhi Y, Wu J, et al. (2016) Leaf aging of Amazonian canopy trees as revealed by spectral and physiochemical measurements. New Phytologist, doi:10.1111/nph.13853

Chen JM, Liu J, Cihlar J, Goulden ML (1999) Daily canopy photosynthesis model through temporal and spatial scaling for remote sensing applications. Ecological modelling, 124, 99-119.

Christoffersen BO, Restrepo-Coupe N, Arain MA, et al. (2014) Mechanisms of water supply and vegetation demand govern the seasonality and magnitude of evapotranspiration in Amazonia and Cerrado. Agricultural and Forest meteorology, 191, 33-50.

Clark DB, Mercado LM, Sitch S, et al. (2011) The Joint UK Land Environment Simulator (JULES), model description-Part 2: carbon fluxes and vegetation dynamics. Geoscientific Model Development, 4, 701-722.

Collatz GJ, Ball JT, Grivet C, et al. (1991) Physiological and environmental regulation of stomatal conductance, photosynthesis and transpiration: a model that includes a laminar boundary layer. Agricultural and Forest Meteorology, 54, 107-136.

Cox PM, Pearson D, Booth BB, et al. (2013) Sensitivity of tropical carbon to climate change constrained by carbon dioxide variability. Nature, 494, 341-344.

Dai Y, Zeng X, Dickinson RE, et al. (2003) The common land model. Bulletin of the American Meteorological Society, 84, 1013-1023.

de Gonçalves LG, Borak JS, Costa MH, et al. (2013) Overview of the large-scale biosphereatmosphere experiment in Amazonia Data Model Intercomparison Project (LBA-DMIP). Agricultural and Forest meteorology, 182, 111-127.

dePury DGG, Farquhar GD (1997) Simple scaling of photosynthesis from leaves to canopies without the errors of big-leaf models. Plant, Cell \& Environment, 20, 537-557.

de Weirdt M, Verbeeck H, Maignan F, et al. (2012) Seasonal leaf dynamics for tropical evergreen forests in a process-based global ecosystem model. Geoscientific Model Development, 5, 1091-1108.

Doughty CE, Goulden ML (2008) Seasonal patterns of tropical forest leaf area index and CO2 exchange. Journal of Geophysical Research-Biogeosciences, 113, G00B06, doi:10.1029/2007JG000590. 
Drewry DT, Kumar P, Long S, et al. (2010) Ecohydrological responses of dense canopies to environmental variability: 1. Interplay between vertical structure and photosynthetic pathway.Journal of Geophysical Research: Biogeosciences, 115, G04022, doi: 10.1029/2010JG001340.

Ellsworth DS, Reich PB (1993) Canopy structure and vertical patterns of photosynthesis and related leaf traits in a deciduous forest. Oecologia, 96, 169-178.

Farquhar GD, von Caemmerer S, Berry JA (1980) A biochemical model of photosynthetic CO2 assimilation in leaves of C3 species. Planta, 149, 78-90.

Fisher RA, Muszala S, Verteinstein M, et al. (2015) Taking off the training wheels: the properties of a dynamic vegetation model without climate envelopes. Geosci. Model Dev. Discuss, 8, 3293-3357.

Friedlingstein P, Cox P, Betts R, et al. (2006) Climate-carbon cycle feedback analysis: Results from the C4MIP model intercomparison. Journal of Climate, 19, 3337-3353.

Friedlingstein P, Meinshausen M, Arora VK, et al. (2014) Uncertainties in CMIP5 climate projections due to carbon cycle feedbacks. Journal of Climate, 27, 511-526.

Fu R, Yin L, Li W, et al. (2013) Increased dry-season length over southern Amazonia in recent decades and its implication for future climate projection. Proceedings of the National Academy of Sciences of the United States of America, 110, 18110-18115.

Girardin CA, Malhi Y, Doughty CE, et al. (2016) Seasonal trends of Amazonian rainforest phenology, net primary productivity, and carbon allocation. Global Biogeochemical Cycles, 30, 700-715.

Guan K, Pan M, Li H, et al. (2015) Photosynthetic seasonality of global tropical forests constrained by hydroclimate. Nature Geoscience, 8, 284-289.

Harper A, Cox P, Friedlingstein P, et al. (2016) Improved representation of plant functional types and physiology in the Joint UK Land Environment Simulator (JULES v4. 2) using plant trait information. Geoscientific Model Development Discussions, doi:10.5194/gmd2016-22

He L, Chen JM, Pisek J, et al. (2012) Global clumping index map derived from the MODIS BRDF product. Remote Sensing of Environment, 119, 118-130.

Heskel MA, Atkin OK, Turnbull MH, Griffin KL (2013) Bringing the Kok effect to light: a review on the integration of daytime respiration and net ecosystem exchange. Ecosphere, 4 , $1-14$.

Hutyra LR, Munger JW, Saleska SR, et al. (2007) Seasonal controls on the exchange of carbon and water in an Amazonian rain forest. Journal of Geophysical Research: Biogeosciences, 112, G03008, doi: 10.1029/2006JG000365.

Huntingford C, Zelazowski P, Galbraith D, et al. (2013) Simulated resilience of tropical rainforests to CO2-induced climate change. Nature Geoscience, 6, 268-273.

Kenzo T, Inoue Y, Yoshimura M, et al. (2015) Height-related changes in leaf photosynthetic traits in diverse Bornean tropical rain forest trees. Oecologia, 177, 191-202. 
Kim Y, Knox RG, Longo M, et al. (2012) Seasonal carbon dynamics and water fluxes in an Amazon rainforest. Global Change Biology, 18, 1322-1334.

Kitajima K, Mulkey S, Wright S. (1997a) Decline of photosynthetic capacity with leaf age in relation to leaf longevities for five tropical canopy tree species. American Journal of Botany, 84, 702-702.

Kitajima K, Mulkey S, Wright S (1997b) Seasonal leaf phenotypes in the canopy of a tropical dry forest: photosynthetic characteristics and associated traits. Oecologia, 109, 490-498.

Kumagai T, Ichie T, Yoshimura M, et al. Modeling CO2 exchange over a Bornean tropical rain forest using measured vertical and horizontal variations in leaf-level physiological parameters and leaf area densities. Journal of Geophysical Research: Atmospheres, 111, D10107, doi:10.1029/2005JD006676.

Lee JE, Frankenberg C, van der Tol C, et al. (2013) Forest productivity and water stress in Amazonia: observations from GOSAT chlorophyll fluorescence. Proceedings of the Royal Society of London B: Biological Sciences, 280, 20130171.

Lin YS, Medlyn BE, Duursma RA, et al. (2015) Optimal stomatal behaviour around the world. Nature Climate Change, 5, 459-464.

Lloyd J, Farquhar GD (2008) Effects of rising temperatures and [CO2] on the physiology of tropical forest trees. Philosophical Transactions of the Royal Society B: Biological Sciences, 363, 1811-1817.

Lloyd J, Patino S, Paiva RQ, et al. (2010) Optimisation of photosynthetic carbon gain and within-canopy gradients of associated foliar traits for Amazon forest trees. Biogeosciences, 7, 1833-1859.

Lopes AP, Nelson BW, Wu J, et al. (2016) Leaf flush drives dry season green-up of the Central Amazon. Remote Sensing of Environment, 182, 90-98.

Lowman MD (1992) Leaf growth dynamics and herbivory in five species of Australian rainforest canopy trees. Journal of Ecology, 80, 433-447.

Malhado AC, Costa MH, de Lima FZ, et al. (2009) Seasonal leaf dynamics in an Amazonian tropical forest. Forest ecology and management, 258, 1161-1165.

Medlyn BE, Duursma RA, Eamus D, et al. (2011) Reconciling the optimal and empirical approaches to modelling stomatal conductance. Global Change Biology, 17, 2134-2144.

Medvigy D, Wofsy SC, Munger JW, et al. (2009) Mechanistic scaling of ecosystem function and dynamics in space and time: Ecosystem Demography model version 2. Journal of Geophysical Research: Biogeosciences, 114, G01002, doi: 10.1029/2008JG000812.

Messier C, Parent S, and Bergeron Y. (1998) Effects of overstory and understory vegetation on the understory light environment in mixed boreal forests. Journal of Vegetation Science, 9 , 511-520.

Messier J, McGill BJ, Enquist BJ, Lechowicz MJ. (2016) Trait variation and integration across scales: Is the leaf economic spectrum present at local scales? Ecography, 10.1111/ecog.02006. 
Miyaji K, Silva WS, Paulo TA (1997) Longevity of leaves of a tropical tree, Theobroma cacao, grown under shading, in relation to position within the canopy and time of emergence. New Phytologist, 135, 445-454.

Morton DC, Nagol J, Carabajal CC, et al. (2014) Amazon forests maintain consistent canopy structure and greenness during the dry season. Nature, 506, 221-224.

Morton DC, Rubio J, Cook BD, et al. (2016) Amazon forest structure generates diurnal and seasonal variability in light utilization. Biogeosciences, 13, 2195-2206.

Myneni RB, Yang W, Nemani RR, et al. (2007) Large seasonal swings in leaf area of Amazon rainforests. Proceedings of the National Academy of Sciences, 104, 4820-4823.

Niinemets Ü, Keenan TF, and Hallik L. (2015) A worldwide analysis of within-canopy variations in leaf structural, chemical and physiological traits across plant functional types. New Phytologist, 205, 973-993.

Oleson KW, Lawrence DM, Bonan GB, et al. (2013) Technical description of version 4.5 of the Community Land Model (CLM). NCAR Tech. Note NCAR/TN-503+ STR. National Center for Atmospheric Research, Boulder, CO, 422 pp. doi: 10.5065/D6RR1W7M, 2013.

Pan Y, Birdsey RA, Fang J, et al. (2011) A large and persistent carbon sink in the world's forests." Science, 333, 988-993.

Powell TL, Galbraith DR, Christoffersen BO, et al. (2013) Confronting model predictions of carbon fluxes with measurements of Amazon forests subjected to experimental drought. New Phytologist, 200, 350-365.

Pyle EH, Santoni GW, Nascimento HE, et al. (2008) Dynamics of carbon, biomass, and structure in two Amazonian forests. Journal of Geophysical Research: Biogeosciences, 113, G00B08, doi:10.1029/2007JG000592.

Reich PB, Uhl C, Walters MB, et al. (2004) Leaf demography and phenology in Amazonian rain forest: a census of 40000 leaves of 23 tree species. Ecological Monographs, 74, 3-23.

Restrepo-Coupe N, da Rocha HR, Hutyra LR, et al. (2013) What drives the seasonality of photosynthesis across the Amazon basin? A cross-site analysis of eddy flux tower measurements from the Brasil flux network. Agricultural and Forest Meteorology, 182, $128-144$.

Restrepo-Coupe N, Levine N, Christoffersen BO, et al. (2017) Do dynamic global vegetation models capture the seasonality of carbon fluxes in the Amazon basin? A data-model intercomparison. Global Change Biology, 23, 191-208.

Rice AH, Pyle EH, Saleska SR, et al. (2004) Carbon balance and vegetation dynamics in an oldgrowth Amazonian forest. Ecological Applications, 14, 55-71.

Richardson AD, Hollinger DY, Aber JD, et al. (2007) Environmental variation is directly responsible for short-but not long-term variation in forest-atmosphere carbon exchange. Global Change Biology, 13, 788-803.

Richardson AD \& O'Keefe J. (2009) Phenological differences between understory and overstory. In Phenology of ecosystem processes (pp. 87-117). Springer New York. 
Richardson AD, Anderson RS, Arain MA, et al. (2012) Terrestrial biosphere models need better representation of vegetation phenology: results from the North American Carbon Program Site Synthesis. Global Change Biology, 18, 566-584.

Roberts DA, Nelson BW, Adams JB, et al. (1998) Spectral changes with leaf aging in Amazon caatinga. Trees, 12, 315-325.

Rogers A, Medlyn BE, Dukes JS, et al. (2017) A Roadmap for improving the representation of photosynthesis in Earth System Models. New Phytologist, 213, 22-42.

Ryu Y, Baldocchi DD, Kobayashi H, et al. (2011) Integration of MODIS land and atmosphere products with a coupled-process model to estimate gross primary productivity and evapotranspiration from $1 \mathrm{~km}$ to global scales. Global Biogeochemical Cycles, 25, GB4017, doi:10.1029/2011GB004053.

Saleska SR, Miller SD, Matross DM, et al. (2003) Carbon in Amazon forests: unexpected seasonal fluxes and disturbance-induced losses. Science, 302, 1554-1557.

Saleska SR, Wu J, Guan K, et al. (2016) Brief Communications Arising: Dry season greening of Amazon forests. Nature, 531: E4-E5.

Saatchi SS, Harris NL, Brown S, et al. (2011) Benchmark map of forest carbon stocks in tropical regions across three continents. Proceedings of the National Academy of Sciences, 108, 9899-9904.

Schimel D, Pavlick R, Fisher JB, et al. (2015) Observing terrestrial ecosystems and the carbon cycle from space. Global change biology, 21, 1762-1776.

Sellers PJ (1987) Canopy reflectance, photosynthesis, and transpiration, II. The role of biophysics in the linearity of their interdependence. Remote sensing of Environment, 21, 143-183.

Sellers PJ, Berry JA, Collatz, et al. (1992) Canopy reflectance, photosynthesis, and transpiration. III. A reanalysis using improved leaf models and a new canopy integration scheme. Remote sensing of environment, 42, 187-216.

Serbin SP, Singh A, Desai AR, et al. (2015) Remotely estimating photosynthetic capacity, and its response to temperature, in vegetation canopies using imaging spectroscopy. Remote Sensing of Environment, 167, 78-87

Sitch S, Friedlingstein P, Gruber N, et al. (2015) Recent trends and drivers of regional sources and sinks of carbon dioxide. Biogeosciences, 12, 653-679.

Stark SC, Leitold V, Wu JL, et al. (2012) Amazon forest carbon dynamics predicted by profiles of canopy leaf area and light environment. Ecology letters, 15, 1406-1414.

Stark SC, Enquist BJ, Saleska SR, et al. (2015) Linking canopy leaf area and light environments with tree size distributions to explain Amazon forest demography. Ecology letters, 18, 636645.

Stark SC, Breshears DD, Garcia ES, et al. (2016) Toward accounting for ecoclimate teleconnections: intra-and inter-continental consequences of altered energy balance after vegetation change. Landscape Ecology, 31, 181-194. 
848 Wehr R, Munger JW, McManus JB, et al. (2016) Seasonality of temperate forest photosynthesis 849 and daytime respiration. Nature, 534, 680-683.

850 Wright IJ, Leishman MR, Read C and Westoby M. (2006) Gradients of light availability and leaf 851 traits with leaf age and canopy position in 28 Australian shrubs and trees. Functional Plant 852 Biology, 33, 407-419.

853 Wright SJ, Van Schaik CP (1994) Light and the phenology of tropical trees. American $854 \quad$ Naturalist, 143, 192-199.

$855 \mathrm{Wu}$ J, Albert LP, Lopes AP, Restrepo-Coupe N, et al. (2016a). Leaf development and 856

857

858

859

860

861

862

863

864

865

866 demography explain photosynthetic seasonality in Amazon evergreen forests." Science, 351, 972-976.

Wu J, Chavana-Bryant C, Prohaska N, et al. (2016b). Convergence in relationships between leaf traits, spectra and age across diverse canopy environments and two contrasting tropical forests. New Phytologist, doi:10.1111/nph.10451.

Wu J, Guan K, Hayek M, et al. (2017) Partitioning the extrinsic and intrinsic controls on gross ecosystem productivity at hourly to inter-annual time scales in an Amazonian evergreen forest. Global Change Biology, 3, 1240-1257.

Xu X, Medvigy D, Powers JS, et al. (2016) Diversity in plant hydraulic traits explains seasonal and inter-annual variations of vegetation dynamics in seasonally dry tropical forests. $\mathrm{New}$ Phytologist, 212, 80-95.

867

868 
870 Table 1. Correlations between the seasonality of eddy covariance derived GPP ref $_{\text {and }}$ the 871 seasonality of modeled $\mathrm{GPP}_{\text {ref }}$ using three different models parameterized by four different 872 inputs of leaf phenology. $\mathrm{R}^{2}$ for coefficient of determination; $\mathrm{p}$, or $\mathrm{p}$-value, for significance of the 873 test; within-canopy phenological variation for the two-fraction leaf, two-layer canopy model was 874 parameterized when ftop $=0.7$; NA for not applicable.

\begin{tabular}{ccccc}
\hline Model $\backslash$ Phenology & Quantity & Quality & Quantity+Quality & $\begin{array}{c}\text { Quantity+Quality+Within- } \\
\text { Canopy Variation }\end{array}$ \\
\hline DF1997 & $\left(\mathrm{R}^{2}=0.19 ; \mathrm{p}=0.041\right)$ & $\left(\mathrm{R}^{2}=0.69 ; \mathrm{p}<0.0001\right)$ & $\left(\mathrm{R}^{2}=0.80 ; \mathrm{p}<0.0001\right)$ & NA \\
ML & $\left(\mathrm{R}^{2}=0.17 ; \mathrm{p}=0.042\right)$ & $\left(\mathrm{R}^{2}=0.72 ; \mathrm{p}<0.0001\right)$ & $\left(\mathrm{R}^{2}=0.81 ; \mathrm{p}<0.0001\right)$ & NA \\
$\begin{array}{c}\text { Two-fraction leaf, } \\
\text { two-layer canopy }\end{array}$ & $\left(\mathrm{R}^{2}=0.17 ; \mathrm{p}=0.042\right)$ & $\left(\mathrm{R}^{2}=0.72 ; \mathrm{p}<0.0001\right)$ & $\left(\mathrm{R}^{2}=0.81 ; \mathrm{p}<0.0001\right)$ & $\left(\mathrm{R}^{2}=0.90 ; \mathrm{p}<0.0001\right)$ \\
\hline
\end{tabular}

875 
877 Figure 1. Mean annual cycles of monthly LAI in three age classes (three different color lines) at 878 the Tapajós k67 site (adapted from Fig. 3A in Wu et al., 2016a). The three-age LAI seasonality 879 was modeled using the same leaf age residence time parameter as Wu et al (2016a), constrained 880 to sum to total camera-observed LAI (black squares) at the same forest site. Shading indicates 881 the dry season.

882 Figure 2. Vertical change in leaf level $\mathrm{V}_{\mathrm{cmax} 25}$ with cumulative LAI from canopy top to forest 883 floor, using the eqns. 5-6, following Lloyd et al (2010). Three color lines represent leaves at 884 three age classes (Young: 1-2 months; Mature: 3-5 months; Old: $\geq 6$ months) respectively. $885 \mathrm{~V}_{\mathrm{cmax} 25}$ of three age classes at the top of the canopy are derived from leaf level gas exchange 886 measurements at the Tapajós $\mathrm{k} 67$ site $(\mathrm{n}=5$ tree species; also see Wu et al., 2016a).

887 Figure 3. Seasonal variation in EC-derived $\mathrm{GPP}_{\text {ref }}$ (seven-year mean annual cycle; black 888 squares) and modeled $\mathrm{GPP}_{\text {ref }}$ (grey circles) incorporating different phenological components, 889 using the two-fraction leaf, two-layer canopy model. (a) modeled GPP ref $_{\text {parameterized by }}$ seasonal variation in leaf quantity (or LAI) only; (b) modeled GPP ref $_{\text {parameterized by seasonal }}$ variation in both leaf quantity and quality, while assuming a constant leaf turnover rate throughout the vertical canopy profile; (c) modeled GPP ${ }_{\text {ref }}$ parameterized by seasonal variation in leaf quantity and quality, and differential leaf turnover rates within a forest canopy (i.e. ftop=0.7). Shading indicates the dry season; ftop refers to the fraction of observed leaf turnover across the whole forest canopy attributed to leaves in the upper canopy layer.

896 Figure 4. Differential photosynthetic sensitivity of the canopy sunlit fraction and the canopy shade fraction to seasonal variation in leaf quantity (Fig. 1) and leaf quality (Fig. 1 and eqn. 1) at the Tapajós k67 site assessed by using the two-fraction leaf, two-layer canopy model under the reference environment: (a) canopy absorbed PAR, (b) canopy LAI, (c) canopy integrated $\mathrm{V}_{\text {cmax }}$, and (d) canopy GPP ref. Data are shown for total canopy (black circles), the sunlit canopy fraction (black triangles) and the shaded canopy fraction (grey triangles); canopy-scale $\mathrm{V}_{\mathrm{cmax}}$ (of perground area) is the sum of canopy LAI weighted by leaf level $\mathrm{V}_{\mathrm{cmax}}$ (see Table $\mathrm{S} 3$ for equations), and since the LAI of the shade canopy fraction is higher than the LAI of the sunlit canopy fraction, as such $\mathrm{V}_{\mathrm{cmax}}$ of the shade canopy fraction is higher than $\mathrm{V}_{\mathrm{cmax}}$ of the sunlit canopy fraction; shading indicates the dry season.

906 Figure 5. Assessing the effect of within-canopy phenological variation (i.e. ftop) on canopy 907 photosynthetic seasonality using the two-fraction leaf, two-layer canopy model. (a) Modeled 908 annual cycles of $\mathrm{GPP}_{\text {ref }}$ (relative to annual maxima) under different ftop values from 0.2 to 1.0; 909 and (b) $\mathrm{R}^{2}$ between modeled and EC-derived GPP ref seasonality plotted against ftop. Shading 910 indicates dry season; ftop refers to the fraction of observed leaf turnover across the whole forest 911 canopy attributed to leaves in the upper canopy layer. 
914 Figure S1. The sensitivity of modeled canopy-scale GPP using the multi-layer model (ML) to 915 the number of layers used for model simulation, under (a) highly cloudy environment (PAR $\left.916 \mathrm{~b}, 0=10.1 \mu \mathrm{mol} \mathrm{m}^{-2} \mathrm{~s}^{-1} \mathrm{Vs} . \mathrm{PAR}_{\mathrm{d}, 0}=260.3 \mu \mathrm{mol} \mathrm{m}^{-2} \mathrm{~s}^{-1}\right)$, (b) intermediate cloudy environment $917 \quad\left(\mathrm{PAR}_{\mathrm{b}, 0}=743.9 \mu \mathrm{mol} \mathrm{m}^{-2} \mathrm{~s}^{-1} \mathrm{vs} . \mathrm{PAR}_{\mathrm{d}, 0}=268 . \mu \mathrm{mol} \mathrm{m}^{-2} \mathrm{~s}^{-1}\right)$, and (c) clear sky environment $918 \quad\left(\mathrm{PAR}_{\mathrm{b}, 0}=1850.5 \mu \mathrm{mol} \mathrm{m} \mathrm{m}^{-2}\right.$ vs. $\left.\mathrm{PAR}_{\mathrm{d}, 0}=173.7 \mu \mathrm{mol} \mathrm{m} \mathrm{s}^{-1} \mathrm{~s}^{-1}\right)$. For model simulation, $\mathrm{PAR}_{\mathrm{b}, 0}$ for 919 canopy surface direct beam and $P A R_{d, 0}$ for canopy surface diffuse beam; solar zenith angle $=30^{\circ}$, $\mathrm{LAI}=6 \mathrm{~m}^{2} \mathrm{~m}^{-2}$, leaf temperature $=28^{\circ} \mathrm{C}$; ambient $\mathrm{CO}_{2}$ concentration $=380 \mathrm{ppm} ; \mathrm{V}_{\mathrm{cmax} 25}=40 \mu \mathrm{mol}$ $\mathrm{CO}_{2} \mathrm{~m}^{-2} \mathrm{~s}^{-1}$.

922

923

924

925

926

927

928

929

930

931

932

933

934

935

936

937

938

939

940

941

942

943

944
Figure S2. The sensitivity analysis of LAI cutoff (which divides the canopy into upper and lower canopy layers) on modeled canopy-scale $\mathrm{GPP}_{\text {ref }}$ seasonality parameterized by field derived leaf quantity and quality by using the two-fraction leaf, two-layer canopy model under three different ftop values: (a) ftop $=0.4$, (b) ftop $=0.6$, and (c) ftop $=0.8$. Three color lines represent different LAI cutoff. Shading indicates the dry season.

Figure S3. Cross model comparisons for canopy-scale GPP-PAR relationship between DF1997 (red line) and ML (black line). For model simulation, solar zenith angle $=30^{\circ}, \mathrm{LAI}=6 \mathrm{~m}^{2} \mathrm{~m}^{-2}$, leaf temperature $=28^{\circ} \mathrm{C}$; ambient $\mathrm{CO}_{2}$ concentration $=380 \mathrm{ppm} ; \mathrm{V}_{\mathrm{cmax} 25}=40 \mu \mathrm{mol} \mathrm{CO} \mathrm{Cm}^{-2} \mathrm{~s}^{-1}$.

Figure S4. Average annual cycle of modeled FAPAR (relative to annual maxima) using the twofraction leaf, two-layer canopy model at the Tapajós k67 site under three scenarios: whole canopy (black circles), the sunlit canopy fraction (black triangles), and the shade canopy fraction (grey triangles). Shading indicates the dry season.

Figure S5. GPP-PAR relationship simulated by the FvCB model under each given $\mathrm{V}_{\mathrm{cmax} 25}$ (in $\mu \mathrm{mol} \mathrm{CO}_{2} \mathrm{~m}^{2} \mathrm{~s}^{-1}$; represented as different color lines).

Figure S6. Average annual cycle of $\mathrm{GPP}_{\text {ref }}$ (relative to annual maxima) at the Tapajós k67 site under four scenarios: eddy covariance derived $\mathrm{GPP}_{\text {ref }}$ (red line), and modeled GPP ref by using the two-fraction leaf, two-layer canopy model for the whole canopy (black circles), for the canopy of sunlit fraction (black triangles), and for the canopy of shade fraction (grey triangles). Shading indicates the dry season. 
945 Table S1. Individual canopy trees for leaf gas exchange measurements of top-of-canopy sunlit 946 leaves in 2012 campaign at the Tapajós k67 site (adapted from Wu et al., 2016a). Species

947 represented by these individuals account for $23.7 \%$ of basal area of vegetative community at the

$948 \quad \mathrm{k} 67$ site. NA for not applicable.

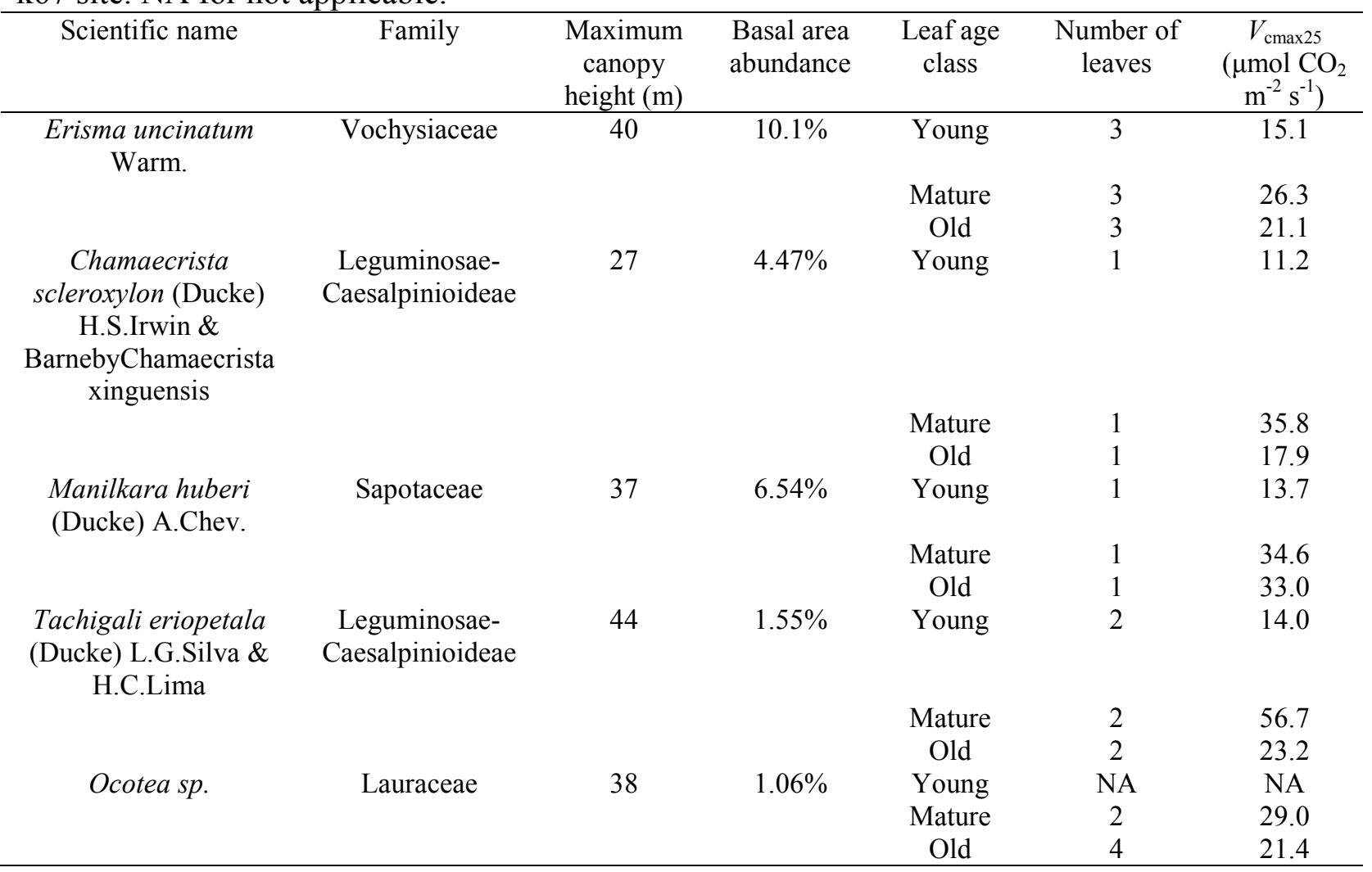


Table S2. Modified equations of the Farquhar, von Caemmerer and Berry (FvCB; Farquhar et al., 1980) leaf photosynthesis model, coupled with Medlyn type stomatal conductance scheme (Medlyn et al., 2011). Symbols of constant are defined in Table S6, and values of the Rubisco parameters are given in Table S7.

\begin{tabular}{|c|c|c|c|}
\hline Equations & Definition & No. & Ref. \\
\hline$G P P_{l}=\min \left\{A_{v}, A_{j}, A_{s}\right\}-R_{l}$ & $\begin{array}{l}\text { Leaf level gross primary productivity } \\
\left(\mathrm{GPP}, \mu \mathrm{mol} \mathrm{CO} \mathrm{C}_{2} \mathrm{~m}^{-2} \mathrm{~s}^{-1}\right)\end{array}$ & 1 & A \\
\hline$A_{v}=\max \left\{V_{c \max } \times \frac{C_{i}-\Gamma_{*}}{C_{i}+K^{\prime}}, 0\right\}$ & $\begin{array}{l}\text { Rubisco-limited photosynthesis }(\mu \mathrm{mol} \\
\left.\mathrm{CO}_{2} \mathrm{~m}^{-2} \mathrm{~s}^{-1}\right)\end{array}$ & 2 & A \\
\hline$K^{\prime}=K_{C} \times\left(1+\frac{O}{K_{O}}\right)$ & Effective Michaelis-Menten Constant & 3 & A \\
\hline$A_{j}=\max \left\{J \times \frac{C_{i}-\Gamma_{*}}{4 \times\left(C_{i}+2 \times \Gamma_{*}\right)}, 0\right\}$ & $\begin{array}{l}\text { Electron-transport limited rate of } \\
\text { photosynthesis }\left(\mu \mathrm{mol} \mathrm{CO} \mathrm{Cm}_{2}^{-2} \mathrm{~s}^{-1}\right)\end{array}$ & 4 & A \\
\hline$J_{e}=\Phi_{P S I I, \max } \times \alpha \times \beta \times Q$ & $\begin{array}{l}\text { The rate of whole electron transport }(\mu \mathrm{mol} \\
\left.\mathrm{m}^{-2} \mathrm{~s}^{-1}\right)\end{array}$ & 5 & $\mathrm{C}$ \\
\hline$J=\frac{J_{e}+J_{\max }-\sqrt{\left(J_{e}+J_{\max }\right)^{2}-4 \times \Theta \times J_{e} \times} J_{\max }}{2 \times \Theta}$ & $\begin{array}{l}\text { The rate of electrons through the thylakoid } \\
\text { membrane }\left(\mu \mathrm{mol} \mathrm{CO} \mathrm{m}^{-2} \mathrm{~s}^{-1}\right)\end{array}$ & 6 & A \\
\hline$A_{s}=0.5 \times V_{c \max }$ & $\begin{array}{l}\text { Triose phosphate export limited rate of } \\
\text { photosynthesis }\left(\mu \mathrm{mol} \mathrm{CO} \mathrm{C}_{2}^{-2} \mathrm{~s}^{-1}\right)\end{array}$ & 7 & B \\
\hline Parameter $=$ Parameter $_{25} \times \exp \left(\frac{\left(T_{K}-298\right) \times \Delta H_{a}}{R \times T_{K} \times 298}\right)$ & $\begin{array}{l}\text { Temperature functions for parameters that } \\
\text { are based on Rubisco kinetic properties } \\
\text { and do not have an optimum within a } \\
\text { biologically significant temperature range } \\
\left(K_{C}, K_{O}, \Gamma_{*}, R_{l} \text {, and in most cases } V_{c \max 25}\right)\end{array}$ & 8 & $\mathrm{C}$ \\
\hline$J_{\max }=J_{\max 25} \times \frac{e^{-\left(\frac{T_{L}-T_{o p t}}{\Omega_{T}}\right)}}{e^{-\left(\frac{25-T_{o p t}}{\Omega_{T}}\right)}}$ & $\begin{array}{l}\text { Temperature function for maximum } \\
\text { electron transport rate, } J_{\max }\end{array}$ & 9 & C, D \\
\hline$\Omega_{T}=11.6+0.18 \times T_{o p t}$ & $\begin{array}{l}\text { Coefficient for temperature function of } \\
J_{\max }\end{array}$ & 10 & C, D \\
\hline$J_{\max 25}=1.67 \times V_{c \max 25}$ & $\begin{array}{l}\text { Linear scaling relationship between } \\
J_{\max 25} \text { and } V_{c \max 25}\end{array}$ & 11 & E, F \\
\hline$T_{K}=T_{l}+273.15$ & Leaf temperature in Kelvin & 12 & $\mathrm{C}$ \\
\hline$R_{l 25}=0.015 \times V_{c \max 25}$ & $\begin{array}{l}\text { Leaf dark respiration at } 25^{\circ} \mathrm{C} \\
\left(\mu \mathrm{mol} \mathrm{CO} \mathrm{C}_{2}^{-2} \mathrm{~s}^{-1}\right)\end{array}$ & 13 & E \\
\hline $\begin{array}{l}g_{s}=1.6 \times\left(1+\frac{g_{1}}{\sqrt{V P D}}\right) \times \frac{G P P_{l}}{C_{a}} \\
G P P_{l}=g_{s} \times\left(C_{a}-C_{i}\right) \\
\Rightarrow C_{i}=C_{a} \times\left(1-\frac{1}{1.6 \times\left(1+\frac{g_{1}}{\sqrt{V P D}}\right)}\right)\end{array}$ & $\begin{array}{l}\text { Use optimal stomatal model to estimate } \\
\text { internal } \mathrm{CO}_{2} \text { concentration }\left(C_{i}\right) \text { from } \\
\text { atmospheric } \mathrm{CO}_{2} \text { concentration }\left(C_{a}\right) \text { and } \\
\text { vapor pressure deficit (VPD) }\end{array}$ & 14 & G \\
\hline
\end{tabular}


958 Table S3. Modified equations of $\mathrm{V}_{\mathrm{cmax}}$ for the canopy of sunlit and shade fractions. Symbols of 959 constant are defined in Table S6, and values of the Rubisco parameters are given in Table S7.

960

\begin{tabular}{|c|c|c|c|}
\hline Equations & Definition & No. & Ref. \\
\hline$V_{c \text { max }, t o t}=\frac{V_{c \max , 0}}{k_{n}} \times\left(1-\exp ^{\left(-k_{n} \times L A I_{t o t}\right)}\right)$ & Canopy total $V_{c \max }\left(\mu \mathrm{mol} \mathrm{CO} \mathrm{Cm}^{-2} \mathrm{~s}^{-1}\right)$ & 15 & A \\
\hline$V_{c \text { max }, \text { sun }}=\frac{V_{c \max , 0} \times \Omega}{k_{n}+k_{b} \times \Omega} \times\left(1-\exp ^{\left(-\left(k_{n}+k_{b} \times \Omega\right) \times L A I_{\text {tot }}\right)}\right)$ & $\begin{array}{l}V_{c \max } \text { for the canopy of sunlit cohort }(\mu \mathrm{mol} \\
\left.\mathrm{CO}_{2} \mathrm{~m}^{-2} \mathrm{~s}^{-1}\right)\end{array}$ & 16 & A, B \\
\hline$V_{c \max , \text { shade }}=V_{c \max , \text { tot }}-V_{c \max , \text { sun }}$ & $\begin{array}{l}V_{c \max } \text { for the canopy of shade cohort }(\mu \mathrm{mol} \\
\left.\mathrm{CO}_{2} \mathrm{~m}^{-2} \mathrm{~s}^{-1}\right)\end{array}$ & 17 & A, B \\
\hline$k_{n}=\exp ^{\left(0.00963 \times V_{c \max , 0}-2.43\right)}$ & $\begin{array}{l}\text { Coefficient of } V_{c m a x} \text { decline within a forest } \\
\text { canopy }\end{array}$ & 18 & $\mathrm{H}$ \\
\hline$k_{b}=\frac{0.5}{\cos (S Z A)}$ & $\begin{array}{l}\text { Beam radiation extinction coefficient of } \\
\text { the canopy }\end{array}$ & 19 & A \\
\hline
\end{tabular}

A: Farquhar et al., 1980; B: Ryu et al., 2011; H: Lloyd et al., 2010. 
Table S4. Modified equations of absorbed photosynthetically active radiation (PAR) by the canopy of sunlit and shade fractions. Symbols of constant are defined in Table S6, and values of the Rubisco parameters are given in Table S7.

967

\begin{tabular}{|c|c|c|c|}
\hline Equations & Definition & No. & Ref. \\
\hline $\begin{aligned} Q_{t o t} & =\left(1-\rho_{c b}\right) \times P A R_{b, 0} \times\left(1-\exp ^{-k_{b}^{\prime} \times L A I_{t o t} \times \Omega}\right) \\
& +\left(1-\rho_{c d}\right) \times P A R_{d, 0} \times\left(1-\exp ^{-k_{d}^{\prime} \times L A I_{t o t} \times \Omega}\right)\end{aligned}$ & $\begin{array}{l}\text { Canopy absorbed total radiation }\left(\mu \mathrm{mol} \mathrm{m}{ }^{-2}\right. \\
\left.\mathrm{s}^{-1}\right)\end{array}$ & 20 & A, B \\
\hline$Q_{b, \text { sun }}=P A R_{b, 0} \times(1-\sigma) \times\left(1-\exp ^{-k_{b} \times L A I_{\text {tot }} \times \Omega}\right)$ & $\begin{array}{l}\text { The absorbed incoming beam radiation by } \\
\text { sunlit leaves }\left(\mu \mathrm{mol} \mathrm{m} \mathrm{m}^{-1}\right)\end{array}$ & 21 & A, B \\
\hline$Q_{d, \text { sun }}=P A R_{d, 0} \times\left(1-\rho_{c d}\right) \times\left(1-\exp ^{-\left(k_{d}^{\prime}+k_{b}\right) \times L A I_{t o t} \times \Omega}\right)$ & $\begin{array}{l}\text { The absorbed incoming diffuse radiation } \\
\text { by sunlit leaves }\left(\mu \mathrm{mol} \mathrm{m} \mathrm{m}^{-1}\right)\end{array}$ & 22 & A, B \\
\hline $\begin{aligned} Q_{s, \text { sun }}= & P A R_{b, 0} \times\left[\left(1-\rho_{c b}\right) \times\left(1-\exp ^{-\left(k_{b}^{\prime}+k_{b}\right) \times L A I_{t o t} \times \Omega}\right) \times \frac{k_{b}^{\prime}}{k_{b}^{\prime}+k_{b}}\right. \\
& \left.-(1-\sigma) \times\left(1-\exp ^{-2 \times k_{b} \times L A A_{t o t} \times \Omega}\right) \times \frac{1}{2}\right]\end{aligned}$ & $\begin{array}{l}\text { The absorbed incoming scattered radiation } \\
\text { by sunlit leaves }\left(\mu \mathrm{mol} \mathrm{m} \mathrm{s}^{-1}\right)\end{array}$ & 23 & A, B \\
\hline$Q_{\text {sun }}=Q_{b, \text { sun }}+Q_{d, \text { sun }}+Q_{s, \text { sun }}$ & $\begin{array}{l}\text { Canopy absorbed total radiation for sunlit } \\
\text { leaves }\left(\mu \mathrm{mol} \mathrm{m} \mathrm{m}^{-1}\right)\end{array}$ & 24 & A, B \\
\hline$Q_{\text {shade }}=Q_{\text {tot }}-Q_{\text {sun }}$ & $\begin{array}{l}\text { Canopy absorbed total radiation for shade } \\
\text { leaves }\left(\mu \mathrm{mol} \mathrm{m} \mathrm{m}^{-1}\right)\end{array}$ & 25 & A, B \\
\hline$k_{b}^{\prime}=\frac{0.46}{\cos (S Z A)}$ & $\begin{array}{l}\text { Beam and scattered beam radiation } \\
\text { extinction coefficient }\end{array}$ & 26 & A \\
\hline$k_{d}^{\prime}=0.719$ & $\begin{array}{l}\text { Diffuse and scattered diffuse radiation } \\
\text { extinction coefficient }\end{array}$ & 27 & $\mathrm{~A}$ \\
\hline
\end{tabular}

A: Farquhar et al., 1980; B: Ryu et al., 2011. 
972 Table S5. Equations to calculate incoming photosynthetically active radiation (PAR) over a 973 canopy. $R_{\text {short }}$ denotes total short-wave radiations from in-situ observations. $P$ denotes observed 974 air pressure and $\mathrm{P}_{0}$ denotes standard air pressure.

\begin{tabular}{|c|c|c|c|}
\hline Equations & Definition & No. & Ref. \\
\hline$R_{b, v i s}=\frac{600 \times e^{-0.185 \times \frac{P}{P_{0}} \times m}}{m}$ & $\begin{array}{l}\text { Expected beam visible radiation under } \\
\text { clear sky }\left(\mathrm{W} \mathrm{m}^{-2}\right)\end{array}$ & 28 & $\mathrm{~N}$ \\
\hline$R_{d, v i s}=\frac{0.4 \times\left(600-R_{b, v i s} \times m\right)}{m}$ & $\begin{array}{l}\text { Expected diffuse visible radiation under } \\
\text { clear sky }\left(\mathrm{W} \mathrm{m}^{-2}\right)\end{array}$ & 29 & $\mathrm{~N}$ \\
\hline$R_{b, n i r}=\frac{720 \times e^{-0.06 \times \frac{P}{P_{0}} \times m}-w}{m}$ & $\begin{array}{l}\text { Expected diffuse visible radiation under } \\
\text { clear sky }\left(\mathrm{W} \mathrm{m}^{-2}\right)\end{array}$ & 30 & $\mathrm{~N}$ \\
\hline$R_{b, n i r}=\frac{720 \times e^{-0.06 \times \frac{P}{P_{0}} \times m}-w}{m}$ & $\begin{array}{l}\text { Expected diffuse near-infrared radiation } \\
\text { under clear sky }\left(\mathrm{W} \mathrm{m}^{-2}\right)\end{array}$ & 31 & $\mathrm{~N}$ \\
\hline$f_{P A R}=\frac{R_{b, v i s}+R_{d, v i s}}{R_{b, n i r}+R_{d, n i r}+R_{b, v i s}+R_{d, v i s}}$ & $\begin{array}{l}\text { The fraction of total PAR over total } \\
\text { incoming radiation }\left(f_{P A R}\right)\end{array}$ & 32 & $\mathrm{~N}$ \\
\hline $\begin{aligned} f_{P A R, b} & =\frac{R_{b, v i s}}{R_{b, v i s}+R_{d, v i s}} \\
& \times\left(1-\left(\frac{0.9-\frac{R_{\text {short }}}{R_{b, n i r}+R_{d, n i r}+R_{b, v i s}+R_{d, v i s}}}{0.7}\right)^{2}\right)\end{aligned}$ & $\begin{array}{l}\text { The fraction of beam PAR over total PAR } \\
\left(f_{P A R, b}\right)\end{array}$ & 33 & $\mathrm{~N}$ \\
\hline$P A R_{b, 0}=R_{\text {short }} \times f_{P A R} \times f_{P A R, b}$ & $\begin{array}{l}\text { The canopy top photosynthetically active } \\
\text { radiation in beam light }\left(P A R_{b, 0}\right)\end{array}$ & 34 & $\mathrm{~N}$ \\
\hline$P A R_{d, 0}=R_{\text {short }} \times f_{P A R} \times\left(1-f_{P A R, b}\right)$ & $\begin{array}{l}\text { The canopy top photosynthetically active } \\
\text { radiation in diffuse }\left(P A R_{d, 0}\right) \text { light }\end{array}$ & 35 & $\mathrm{~N}$ \\
\hline$w=1320 \times 10^{-1.195+0.4459 \times \log _{10} m-0.0345 \times\left(\log _{10} m\right)^{2}}$ & $\begin{array}{l}\text { Expected water absorbance of near- } \\
\text { infrared radiation in the atmosphere } \\
\left(\mathrm{W} \mathrm{m}^{-2}\right)\end{array}$ & 36 & $\mathrm{~N}$ \\
\hline$m=\cos (S Z A)^{-1}$ & $\begin{array}{l}\text { Parameter calculated from solar zenith } \\
\text { angle (SZA) }\end{array}$ & 37 & $\mathrm{~N}$ \\
\hline
\end{tabular}


Table S6. Table of constants used in leaf and canopy level photosynthesis model.

977

\begin{tabular}{|l|l|l|l|}
\hline Symbols & Definition & Values & Ref. \\
\hline $\mathrm{C}_{i}$ & Inter-celluar $\mathrm{CO}_{2}$ concentration $\left(=0.7^{*}\right.$ ambient $\mathrm{CO}_{2}$ concentration; $\left.\mu \mathrm{mol} \mathrm{mol}^{-1}\right)$ & 266 & $\mathrm{~A}$ \\
\hline $\mathrm{O}$ & Oxygen concentration $\left(\mathrm{mmol} \mathrm{mol}^{-1}\right)$ & 205 & $\mathrm{~A}$ \\
\hline$\alpha$ & Leaf absorbance & 0.85 & $\mathrm{~A}, \mathrm{C}$ \\
\hline $\boldsymbol{\beta}$ & Fraction of photosystem II to photosystem I & 0.5 & $\mathrm{~A}, \mathrm{C}$ \\
\hline$\Phi_{P S I I, \max }$ & Maximum quantum efficiency of PSII photochemistry & 0.7 & $\mathrm{C}$ \\
\hline$\Theta$ & Curvature term & 0.7 & $\mathrm{~A}, \mathrm{E}$ \\
\hline $\mathrm{R}$ & Universal gas constant $\left(\mathrm{J} \mathrm{mol}^{-1} \mathrm{~K}^{-1}\right)$ & 8.314 & $\mathrm{~A}$ \\
\hline$V_{c \max 25}$ & Maximal carboxylation rate at $25^{\circ} \mathrm{C}\left(\mu \mathrm{mol} / \mathrm{m}^{2} / \mathrm{s}\right)$ & Observation & $\mathrm{K}$ \\
\hline$T_{\text {opt }}$ & Optimal leaf temperature for $J_{\max }\left({ }^{\circ} \mathrm{C}\right)$ & 35 & $\mathrm{I}$ \\
\hline$V_{c \max , 0}$ & Maximal carboxylation rate for leaves at canopy surface $\left(\mu \mathrm{mol} \mathrm{CO}_{2} \mathrm{~m}^{-2} \mathrm{~s}^{-1}\right)$ & Observation & $\mathrm{K}$ \\
\hline$\Omega$ & Clumping index & 0.66 & $\mathrm{~J}$ \\
\hline$L A I_{t o t}$ & Canopy total leaf area index $\left(\mathrm{m}^{2} / \mathrm{m}^{2}\right)$ & Observation & $\mathrm{K}$ \\
\hline$\rho_{c b}$ & Canopy reflection coefficient for beam radiation & 0.029 & $\mathrm{~A}$ \\
\hline$\rho_{c d}$ & Canopy reflection coefficient for diffuse radiation & 0.036 & $\mathrm{~A}$ \\
\hline$\sigma$ & Leaf scatting coefficient of radiation & 0.15 & $\mathrm{~A}$ \\
\hline $\mathrm{g} 1$ & Slope for stomatal conductance model & 3.77 & $\mathrm{~L}$ \\
\hline
\end{tabular}

978 A: Farquhar et al., 1980; C: Bernacchi et al., 2013; E: Bonan et al., 2014; I: Lloyd \& Farquhar, 979 2008; J: He et al., 2005; K: Wu et al., 2016a; L: Lin et al., 2015. 
982 Table S7. The values for $\mathrm{c}$ and $\Delta H_{a}$ (activation energy) describing the temperature response of 983 the five parameters used to predict $\mathrm{CO}_{2}$ uptake by leaves during Rubisco-limited photosynthesis 984 in leaf level FvCB model (see Table S4) (reference: M: Bernacchi et al., 2001).

985

\begin{tabular}{|l|l|l|l|}
\hline Parameter & Value at $25^{\circ} \mathrm{C}$ & $\mathrm{c}$ (dimensionless) & $\Delta H_{a}\left(\mathrm{~kJ} \mathrm{~mol}^{-1}\right)$ \\
\hline$R_{l}\left(\mu \mathrm{mol} / \mathrm{m}^{2} / \mathrm{s}\right)$ & $R_{l 25}$ & 18.72 & 46.39 \\
\hline$V_{c \max }\left(\mu \mathrm{mol} / \mathrm{m}^{2} / \mathrm{s}\right)$ & $V_{c \max 25}$ & 26.35 & 65.33 \\
\hline$\Gamma_{*}\left(\mu \mathrm{mol} / \mathrm{m}^{2} / \mathrm{s}\right)$ & 42.75 & 19.02 & 37.83 \\
\hline$K_{C}\left(\mu \mathrm{mol} / \mathrm{m}^{2} / \mathrm{s}\right)$ & 404.9 & 38.05 & 79.43 \\
\hline$K_{O}\left(\mathrm{mmol} / \mathrm{m}^{2} / \mathrm{s}\right)$ & 278.4 & 20.30 & 36.38 \\
\hline
\end{tabular}

986

987

988 


\section{References}

[A] Farquhar GD, von Caemmerer S, Berry JA (1980) A biochemical model of photosynthetic $\mathrm{CO} 2$ assimilation in leaves of C3 species. Planta, 149, 78-90.

[B] Ryu Y, Baldocchi DD, Kobayashi H, et al. (2011) Integration of MODIS land and atmosphere products with a coupled-process model to estimate gross primary productivity and evapotranspiration from $1 \mathrm{~km}$ to global scales. Global Biogeochemical Cycles, 25, GB4017, doi:10.1029/2011GB004053.

[C] Bernacchi CJ, Bagley JE, Serbin SP, et al. (2010) Modelling C3 photosynthesis from the chloroplast to the ecosystem. Plant, cell \& environment, 36, 1641-1657.

[D] June T, Evans JR, Farquhar GD. (2004) A simple new equation for the reversible temperature dependence of photosynthetic electron transport: a study on soybean leaf. Functional plant biology, 31, 275-283.

[E] Bonan GB, Williams M, Fisher RA, et al. (2014) Modeling stomatal conductance in the earth system: linking leaf water-use efficiency and water transport along the soil-plantatmosphere continuum. Geoscientific Model Development, 7, 2193-2222.

[F] Medlyn BE, Dreyer E, Ellsworth D, et al. (2002) Temperature response of parameters of a biochemically based model of photosynthesis. II. A review of experimental data. Plant, Cell \& Environment, 25, 1167-1179.

[G] Medlyn BE, Duursma RA, Eamus D, et al. (2011) Reconciling the optimal and empirical approaches to modelling stomatal conductance. Global Change Biology, 17, 2134-2144.

[H] Lloyd J, Patino S, Paiva RQ, et al. (2010) Optimisation of photosynthetic carbon gain and within-canopy gradients of associated foliar traits for Amazon forest trees. Biogeosciences, 7, 1833-1859.

[I] Lloyd J, Farquhar GD (2008) Effects of rising temperatures and [CO2] on the physiology of tropical forest trees. Philosophical Transactions of the Royal Society B: Biological Sciences, 363, 1811-1817.

[J] He L, Chen JM, Pisek J, et al. (2012) Global clumping index map derived from the MODIS BRDF product. Remote Sensing of Environment, 119, 118-130.

[K] Wu J, Albert LP, Lopes AP, Restrepo-Coupe N, Hayek M, Wiedemann KT, Guan K, et al. (2016a). Leaf development and demography explain photosynthetic seasonality in Amazon evergreen forests." Science, 351, 972-976.

[L] Lin YS, Medlyn BE, Duursma RA, et al. (2015) Optimal stomatal behaviour around the world. Nature Climate Change, 5, 459-464.

[M] Bernacchi CJ, Singsaas EL, Pimentel C, A et al. (2001) Improved temperature response functions for models of Rubisco-limited photosynthesis. Plant, Cell \& Environment, 24, 253-259.

[N] Weiss, A., and J. M. Norman. 1985. Partitioning solar radiation into direct and diffuse, visible and near-infrared components. Agricultural and Forest Meteorology, 34, 205-213. 


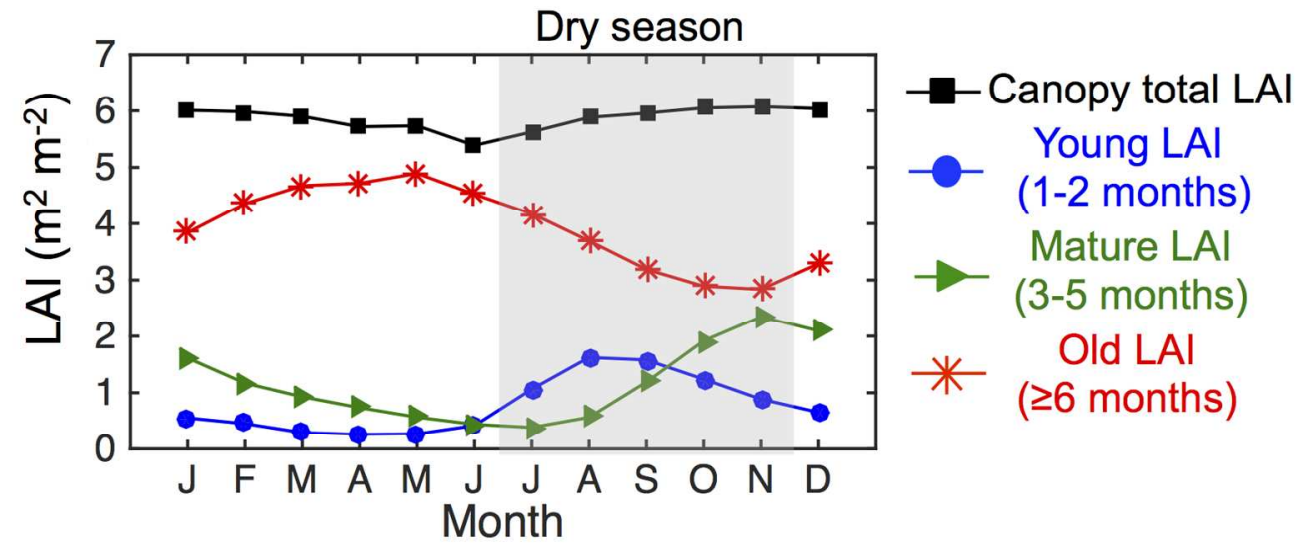

Figure 1. Mean annual cycles of monthly LAI in three age classes (three different color lines) at the Tapajós k67 site (adapted from Fig. 3A in Wu et al., 2016a). The three-age LAI seasonality was modeled using the same leaf age residence time parameter as Wu et al (2016a), constrained to sum to total camera-observed LAI (black squares) at the same forest site. Shading indicates the dry season.

$$
144 \times 62 \mathrm{~mm}(300 \times 300 \mathrm{DPI})
$$




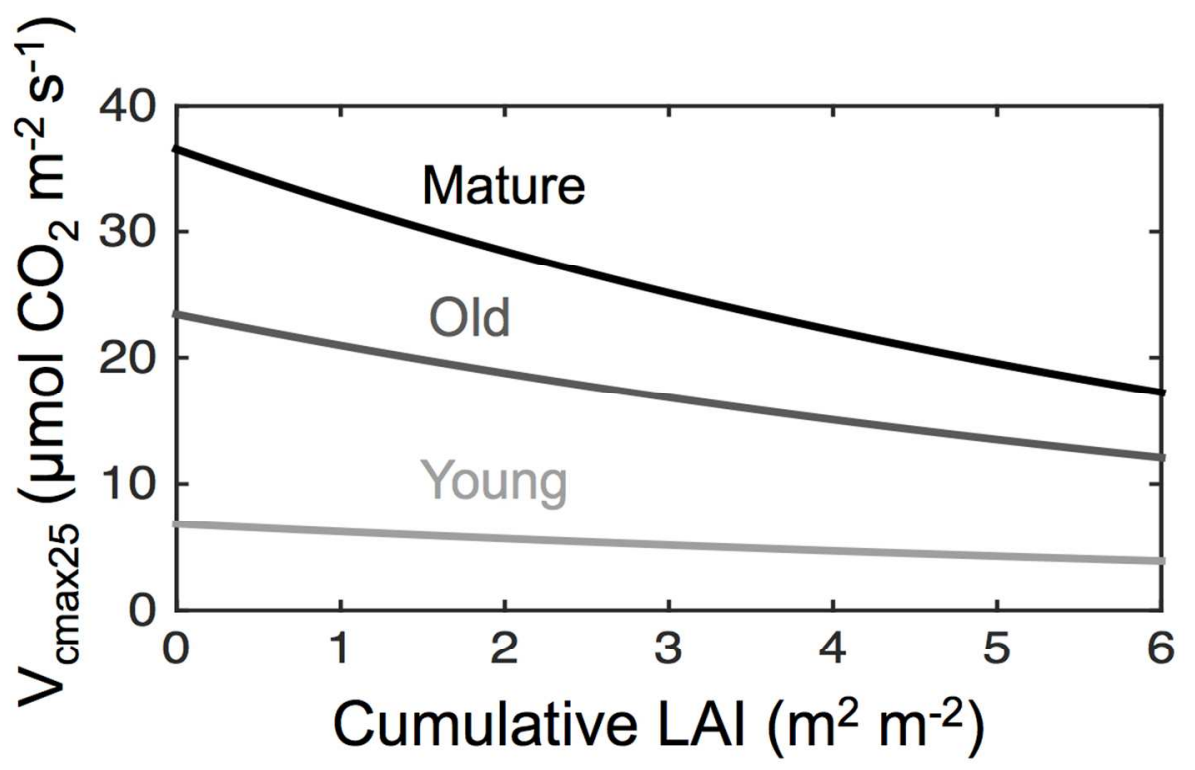

Figure 2. Vertical change in leaf level Vcmax 25 with cumulative LAI from canopy top to forest floor, using the eqns. 5-6, following Lloyd et al (2010). Three color lines represent leaves at three age classes (Young: 1-2 months; Mature: 3-5 months; Old: $\geq 6$ months) respectively. Vcmax25 of three age classes at the top of the canopy are derived from leaf level gas exchange measurements at the Tapajós k67 site $(n=5$ tree species; also see Wu et al., 2016a).

$$
112 \times 65 \mathrm{~mm} \text { ( } 300 \times 300 \mathrm{DPI})
$$



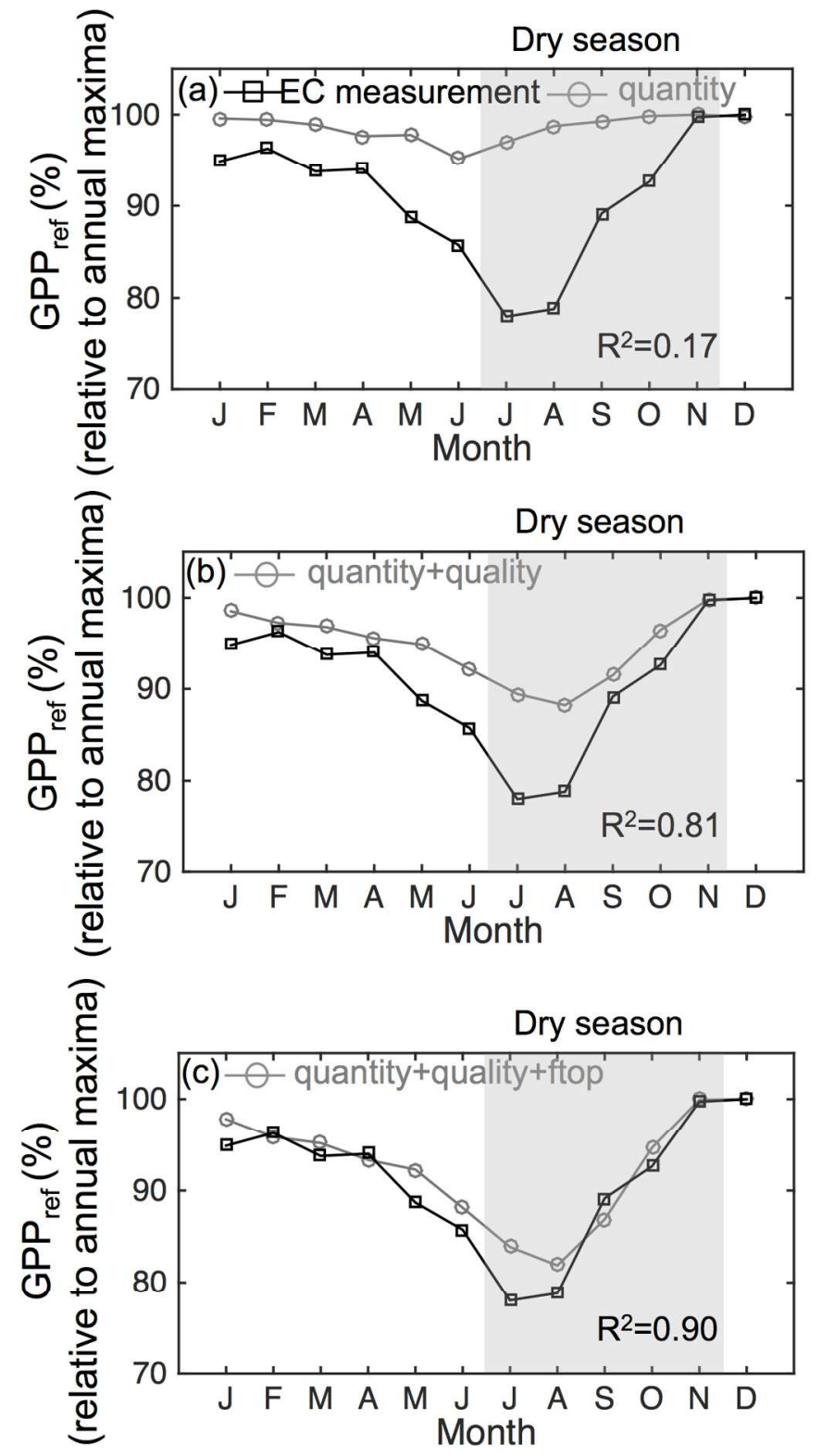

Figure 3. Seasonal variation in EC-derived GPPref (seven-year mean annual cycle; black squares) and modeled GPPref (grey circles) incorporating different phenological components, using the two-fraction leaf, two-layer canopy model. (a) modeled GPPref parameterized by seasonal variation in leaf quantity (or LAI) only; (b) modeled GPPref parameterized by seasonal variation in both leaf quantity and quality, while

assuming a constant leaf turnover rate throughout the vertical canopy profile; (c) modeled GPPref parameterized by seasonal variation in leaf quantity and quality, and differential leaf turnover rates within a forest canopy (i.e. ftop=0.7). Shading indicates the dry season; ftop refers to the fraction of observed leaf turnover across the whole forest canopy attributed to leaves in the upper canopy layer. 


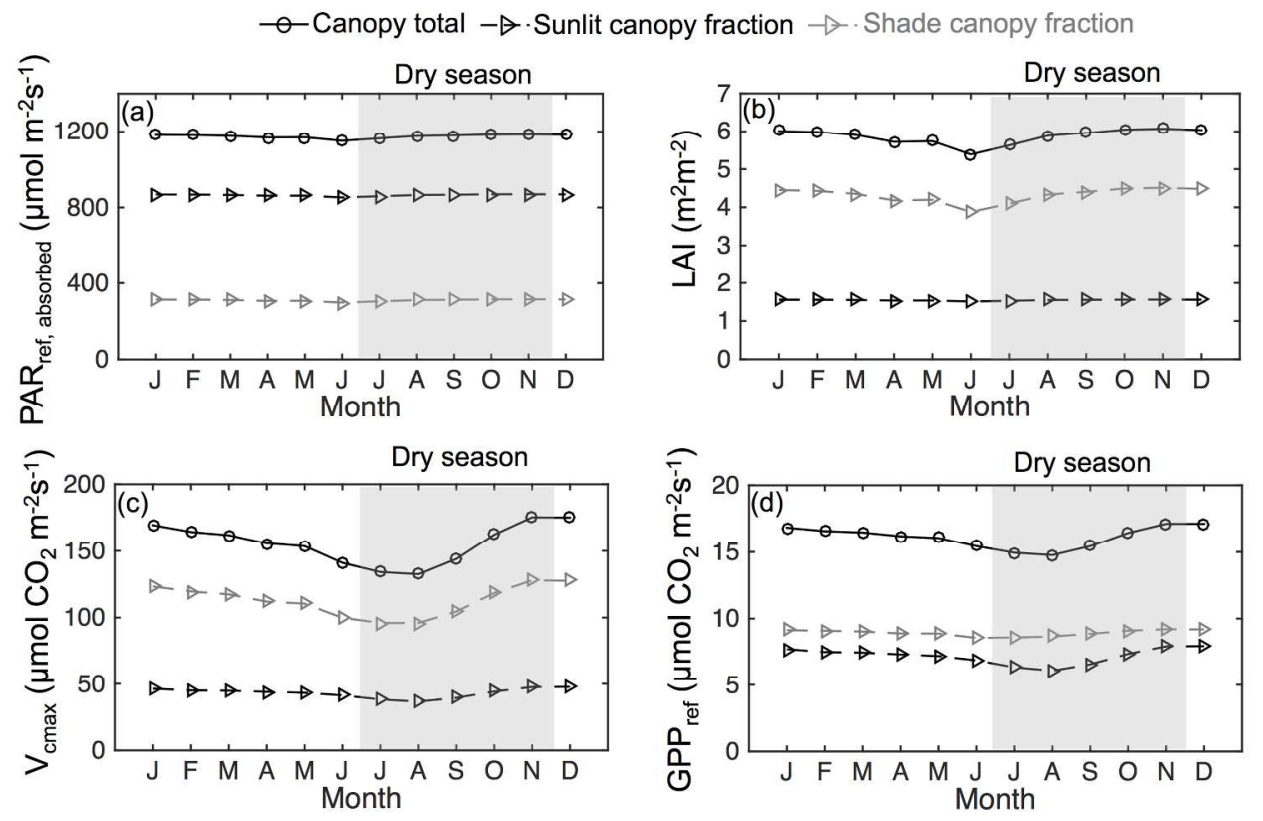

Figure 4. Differential photosynthetic sensitivity of the canopy sunlit fraction and the canopy shade fraction to seasonal variation in leaf quantity (Fig. 1) and leaf quality (Fig. 1 and eqn. 1) at the Tapajós k67 site assessed by using the two-fraction leaf, two-layer canopy model under the reference environment: (a) canopy absorbed PAR, (b) canopy LAI, (c) canopy integrated Vcmax, and (d) canopy GPPref. Data are shown for total canopy (black circles), the sunlit canopy fraction (black triangles) and the shaded canopy fraction (grey triangles); canopy-scale Vcmax (of per-ground area) is the sum of canopy LAI weighted by leaf level Vcmax (see Table S3 for equations), and since the LAI of the shade canopy fraction is higher than the LAI of the sunlit canopy fraction, as such Vcmax of the shade canopy fraction is higher than Vcmax of the sunlit canopy fraction; shading indicates the dry season.

$219 \times 137 \mathrm{~mm}(300 \times 300 \mathrm{DPI})$ 


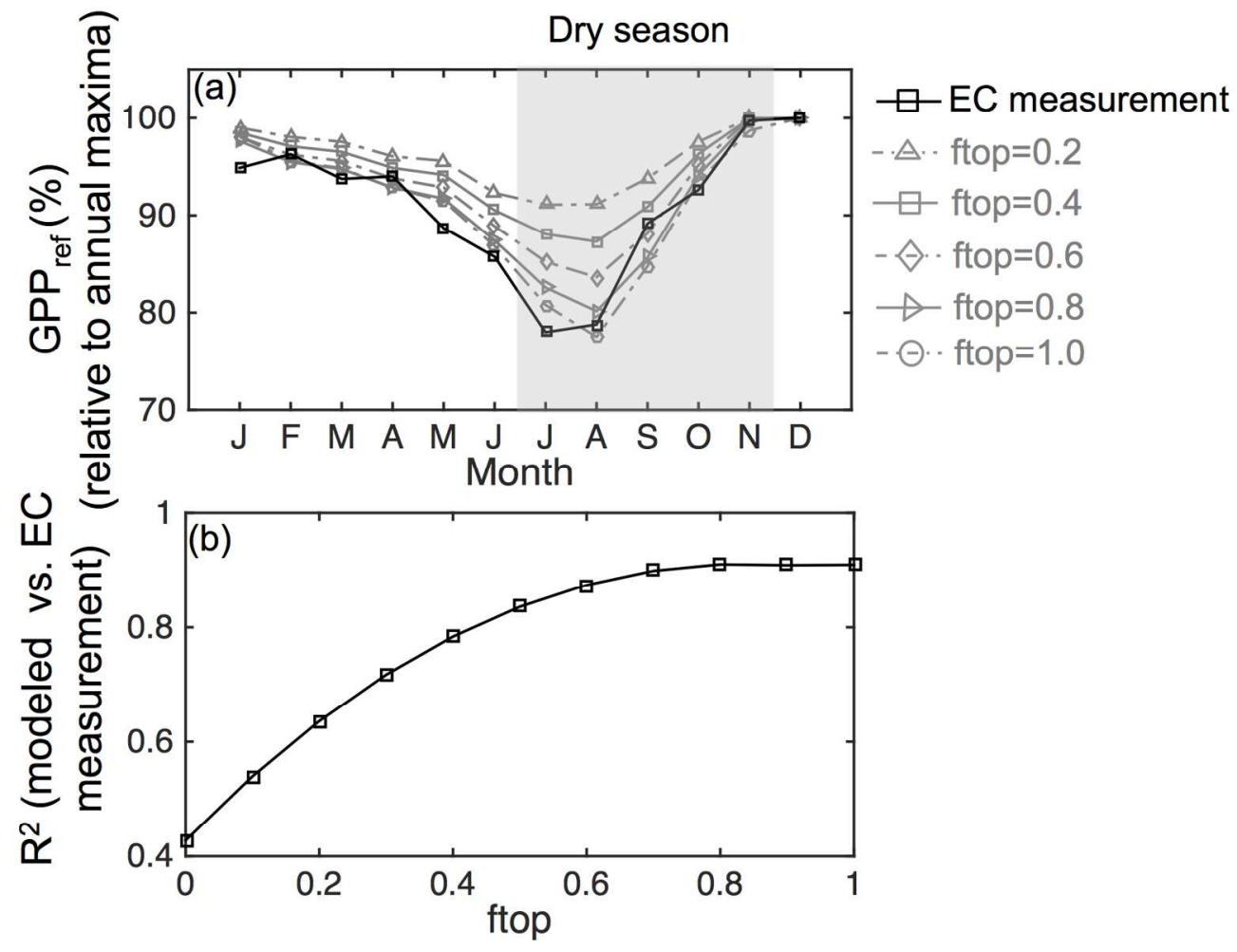

Figure 5. Assessing the effect of within-canopy phenological variation (i.e. ftop) on canopy photosynthetic seasonality using the two-fraction leaf, two-layer canopy model. (a) Modeled annual cycles of GPPref (relative to annual maxima) under different ftop values from 0.2 to 1.0; and (b) R2 between modeled and EC-derived GPPref seasonality plotted against ftop. Shading indicates dry season; ftop refers to the fraction of observed leaf turnover across the whole forest canopy attributed to leaves in the upper canopy layer.

$157 \times 120 \mathrm{~mm}(300 \times 300$ DPI $)$ 